Review Article

\title{
Phytochemicals That Influence Gut Microbiota as Prophylactics and for the Treatment of Obesity and Inflammatory Diseases
}

\author{
Lucrecia Carrera-Quintanar ${ }^{(D)}{ }^{1}$ Rocío I. López Roa $(\mathbb{D})^{2}$ Saray Quintero-Fabián $\mathbb{D}^{3}{ }^{3}$ \\ Marina A. Sánchez-Sánchez, ${ }^{4,2}$ Barbara Vizmanos, ${ }^{5}$ and Daniel Ortuño-Sahagún $\mathbb{D}^{4}$ \\ ${ }^{1}$ Universidad de Guadalajara, Laboratorio de Ciencias de los Alimentos, Departamento de Reproducción Humana, Crecimiento y \\ Desarrollo Infantil, CUCS, Guadalajara, JAL, Mexico \\ ${ }^{2}$ Universidad de Guadalajara, Laboratorio de Investigación y Desarrollo Farmacéutico, Departamento de Farmacobiología, CUCEI, \\ Guadalajara, JAL, Mexico \\ ${ }^{3}$ Universidad Nacional Autónoma de México, Instituto Nacional de Pediatría, Unidad de Genética de la Nutrición, Instituto de \\ Investigaciones Biomédicas, Mexico City, Mexico \\ ${ }^{4}$ Universidad de Guadalajara, Laboratorio de Neuroinmunobiología Molecular, Instituto de Investigación en Ciencias Biomédicas \\ (IICB), CUCS, Guadalajara, JAL, Mexico \\ ${ }^{5}$ Universidad de Guadalajara, Laboratorio de Evaluación del Estado Nutricio, Departamento de Reproducción Humana, Crecimiento \\ y Desarrollo Infantil, CUCS, Guadalajara, JAL, Mexico
}

Correspondence should be addressed to Daniel Ortuño-Sahagún; daniel.ortuno.sahagun@gmail.com

Received 15 September 2017; Revised 17 January 2018; Accepted 13 February 2018; Published 26 March 2018

Academic Editor: Amedeo Amedei

Copyright (c) 2018 Lucrecia Carrera-Quintanar et al. This is an open access article distributed under the Creative Commons Attribution License, which permits unrestricted use, distribution, and reproduction in any medium, provided the original work is properly cited.

\begin{abstract}
Gut microbiota (GM) plays several crucial roles in host physiology and influences several relevant functions. In more than one respect, it can be said that you "feed your microbiota and are fed by it." GM diversity is affected by diet and influences metabolic and immune functions of the host's physiology. Consequently, an imbalance of GM, or dysbiosis, may be the cause or at least may lead to the progression of various pathologies such as infectious diseases, gastrointestinal cancers, inflammatory bowel disease, and even obesity and diabetes. Therefore, GM is an appropriate target for nutritional interventions to improve health. For this reason, phytochemicals that can influence GM have recently been studied as adjuvants for the treatment of obesity and inflammatory diseases. Phytochemicals include prebiotics and probiotics, as well as several chemical compounds such as polyphenols and derivatives, carotenoids, and thiosulfates. The largest group of these comprises polyphenols, which can be subclassified into four main groups: flavonoids (including eight subgroups), phenolic acids (such as curcumin), stilbenoids (such as resveratrol), and lignans. Consequently, in this review, we will present, organize, and discuss the most recent evidence indicating a relationship between the effects of different phytochemicals on GM that affect obesity and/or inflammation, focusing on the effect of approximately 40 different phytochemical compounds that have been chemically identified and that constitute some natural reservoir, such as potential prophylactics, as candidates for the treatment of obesity and inflammatory diseases.
\end{abstract}

\section{Introduction}

Obesity is a chronic state of low-grade inflammation constituting a well-known risk factor for multiple pathological conditions, including metabolic syndrome and insulin resistance [1], and it has also been implicated as a proactive factor and associated with a nonfavorable disease course of chronic autoimmune inflammatory disorders, such as multiple sclerosis (MS) [2]. Several studies over the last decade report interest in fermentation products from gut microbiota (GM) in the control of obesity and related metabolic disorders [3]. GM denotes an entire ecosystem inhabiting each organism, thus constituting a "superorganism" [4]. GM plays several crucial roles in host physiology and influences several relevant functions: it harvests energy from indigestible food, influences fatty 
acid oxidation, fasting, bile acid production, satiety, and lipogenesis, and even influences innate immunity (reviewed in [3]). In more than one respect, we are able to establish that you "feed your microbiota and are fed by it." GM provides signals that promote the production of cytokines, leading to the maturation of immune cells modulating the normal development of immune functions of the host immune system $[5,6]$. Consequently, an imbalance of GM, or dysbiosis, can be the cause or at least lead to the progression of several pathologies such as infectious diseases, gastrointestinal cancers, cardiovascular disease, inflammatory bowel disease, and even obesity and diabetes $[7,8]$. Additionally, a pathological state can cause an imbalance in this microbial ecosystem. For instance, a dysfunction of the innate immune system may be one of the factors that favor metabolic diseases through alteration of the GM [9].

In terms of immune response, the immune system recognizes conserved structural motifs of microbes, called PAMPs (pathogen-associated molecular patterns), by mean of tolllike receptors (TLR), which are expressed in the membrane of sentinel cells [10]. This interaction induces immune responses against microbes through the activation of inflammatory signaling pathways. Therefore, GM, which interacts with epithelial TLR, critically influences immune homeostasis [9]. Although the complete etiology of inflammatory diseases remains unknown, intestinal gut dysbiosis has been associated with a variety of neonatal and children's diseases [4], in which chronic intestinal inflammation and mucosal damage derives from alteration of GM [11].

Diet provides the nutritional supplies for life and growth, and some components exert valuable effects when consumed regularly. These components are called "functional foods" or "nutraceuticals" [12]. Consequently, functional foods contain bioactive substances, nutraceutics, which can be classified as micronutrients (vitamins and fatty acids) and nonnutrients (phytochemicals and probiotics) (see Table 1 in [13]). These components, with a wide range of chemical structures and functionality, provide different beneficial effects beyond simple nutrition, resulting in improved health.

Gut bacterial diversity is mainly affected by the diet, which may also affect its functional relationships with the host [14-17]. During their gastrointestinal passage, the components of the diet are metabolized by intestinal bacteria [18]. Diets rich in carbohydrates and simple sugars lead to Firmicutes and Proteobacteria proliferation, while those rich in saturated fat and animal protein favor Bacteroidetes and Actinobacteria [19]. Microbial diversity of the intestine decreases in diets with higher fat content [16]. Several physiological aspects of the gut environment can be influenced by the diet, then, including absorption of micronutrients, vitamins, and nutraceutics, and changes in $\mathrm{pH}$ of the gut environment, which in turn alters the balance of the GM [20]. Therefore, GM influences the biological activity of food compounds but is also a target for nutritional intervention to improve health [18].

On this basis, phytochemicals, like nutraceuticals that can influence GM, are being studied as coadjuvants to treat obesity and inflammatory diseases. In this review, we will present, organize, and discuss the most recent evidence that points to a relationship of the phytochemical effect on GM that affects obesity and/or inflammation, focusing on the effect of phytochemicals as potential prophylactics and candidates for the treatment of these diseases.

\section{Phytochemicals Can Influence Obesity and Inflammatory Diseases through Affecting GM}

Phytochemicals can be defined as "bioactive nonnutrient plant compounds present in fruits, vegetables, grains, and other plants, whose ingestion has been linked to reductions in the risk of major chronic diseases" [21]. Held to be phytochemicals, prebiotics are nondigestible food components (mainly carbohydrate polymers, such as fructooligosaccharides and mannooligosaccharides) that benefit the human body because they modulate GM through selective stimulation of some bacterial species proliferation in the colon, named "probiotics" [22]. These include endosymbionts such as lactic acid bacteria, bifidobacteria, yeast, and bacilli, which participate in the metabolism of their hosts [13]. Regarded as functional foods, both prebiotics and probiotics have been considered potential constituents of therapeutic interventions that modify GM in an attempt to modulate in turn some inflammatory diseases (comprehensively reviewed in [23]). On the other hand, the remaining phytochemical compounds may be classified on the basis of some common structural features into groups as follows: polyphenols and derivatives, carotenoids, and thiolsulfides, among others (see Table 1 in [13]). Of the latter, the polyphenols represent the largest group.

Polyphenols are secondary metabolites of plants and represent vastly diverse phytochemicals with complex chemical structures. They are commonly present in plant foods, such as cacao, coffee, dry legumes (seeds), fruits (like apples and berries), nuts, olives, some vegetables (such as lettuce and cabbage), tea, and wine. The daily intake of dietary phenols is estimated to be above $1 \mathrm{~g}$, which is 10 times higher than the vitamin $\mathrm{C}$ intake from diet [24]. The interaction between polyphenols and GM has been well established [25]. Polyphenols are frequently conjugated as glycosides, which derive in aglycones when metabolized by GM. Generally, the intestinal metabolism of polyphenols includes hydrolysis of glycosides and esters, reduction of nonaromatic alkenes, and cleavage of the skeletons [26, 27]. Studies have reported that only a low number of polyphenols can be absorbed in the small intestine. The remaining (90-95\%) nonabsorbed polyphenols reach the colon in high concentrations (up into the $\mathrm{mM}$ range), where they are degradated by microbial enzymes before their absorption [28]. Compared to their parent compounds, the permanence in plasma for metabolites is extended and they are finally eliminated in urine $[29,30]$. GM, then, can regulate the health effects of polyphenols, and reciprocally, polyphenols can modulate GM and even interfere with its own bioavailability [31]. 


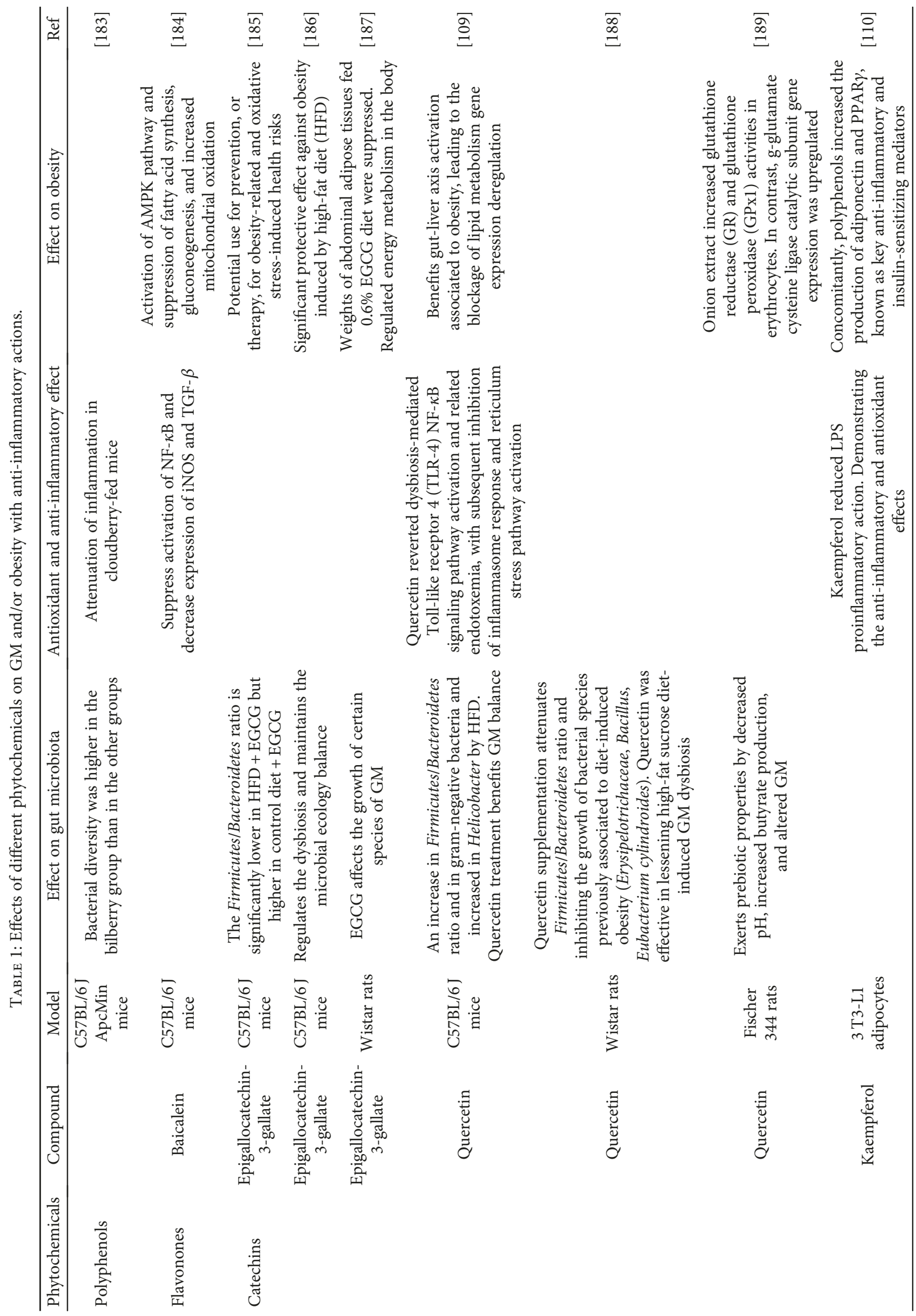




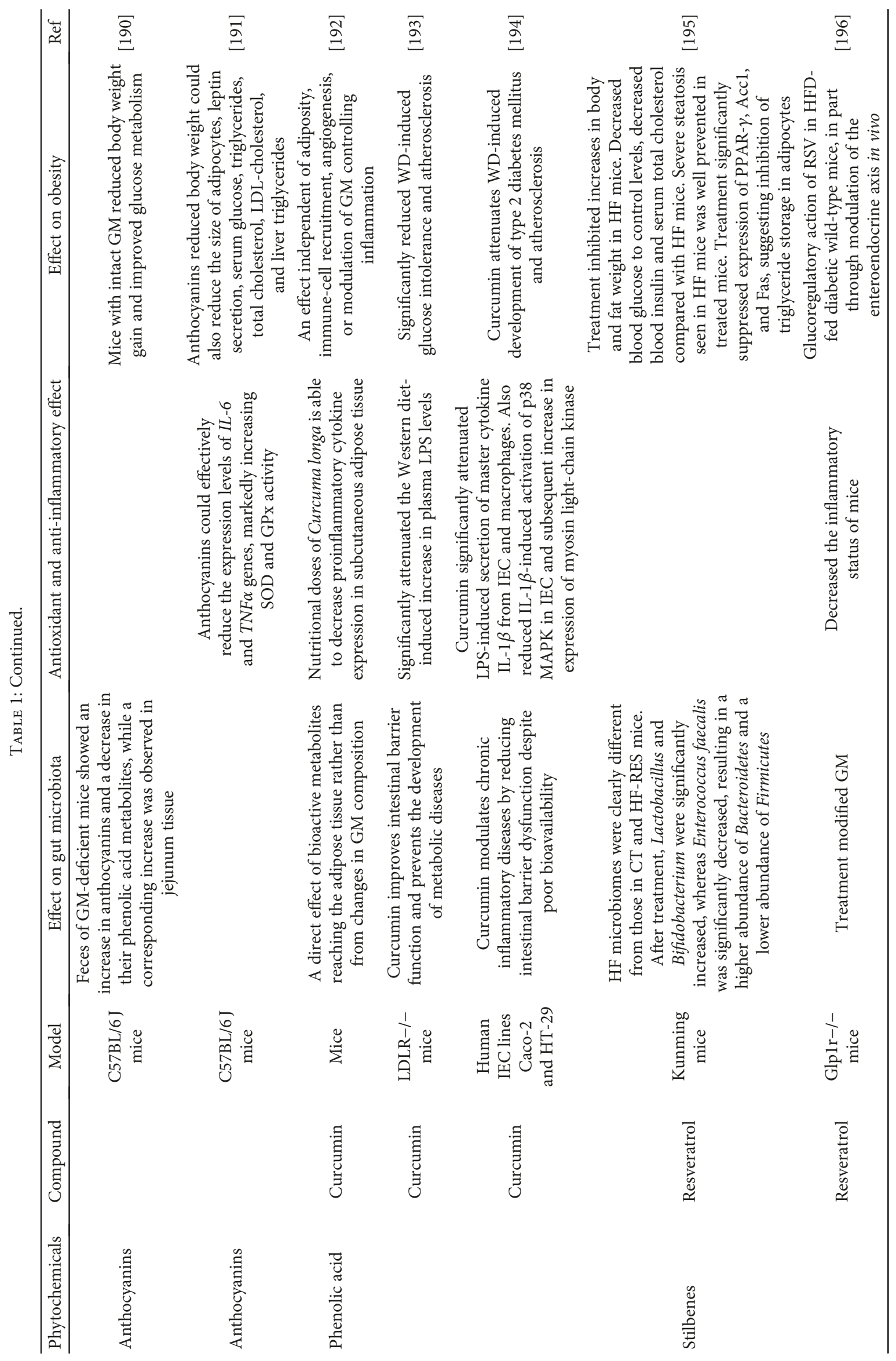




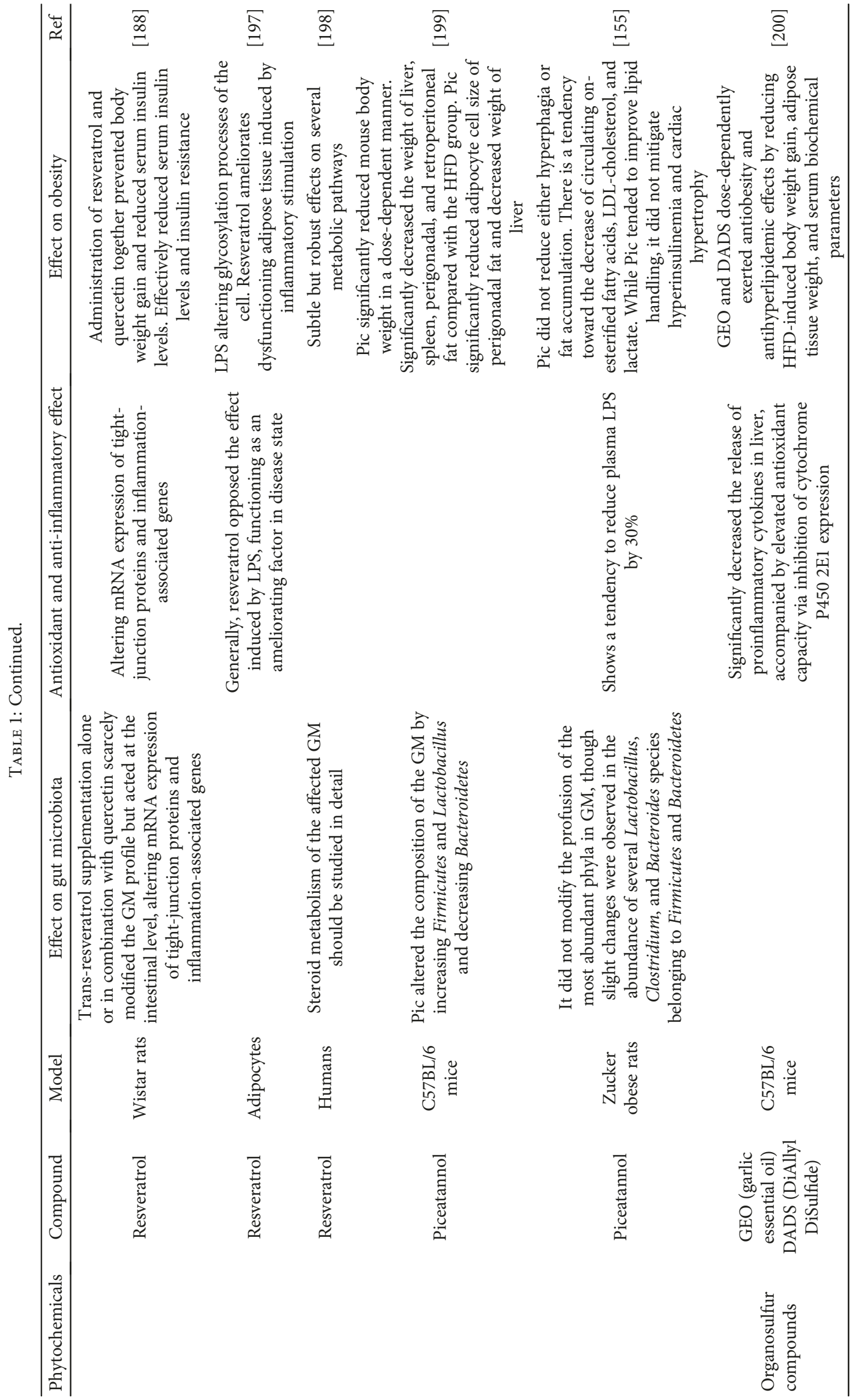


Flavonoid<smiles>O=c1c(O)c(-c2ccc(O)c(O)c2)oc2cc(O)cc(O)c12</smiles>

Quercetin<smiles>COc1cc(/C=C/C(=O)CC(=O)/C=C/c2ccc(O)c(OC)c2)ccc1O</smiles>

Curcumin
Stilbene<smiles>Oc1ccc(/C=C/c2cc(O)cc(O)c2)cc1</smiles>

Resveratrol
Lignan

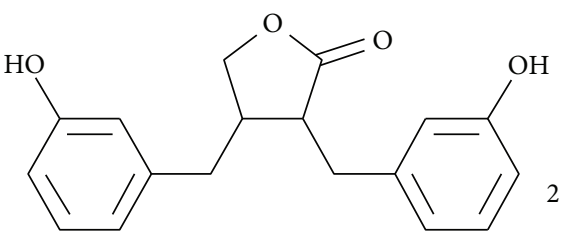

Enterolactone

FIGURE 1: Chemical structure of representative molecules for the four main polyphenol groups.

Approximately 8000 structures of polyphenols have been identified [32], which can be classified into four main groups (Figure 1) as follows: (a) flavonoids (with eight subgroups), (b) phenolic acids (curcumin), (c) stilbenoids (resveratrol), and (d) lignanes. Polyphenols have been extensively studied over the past decade because of their strong antioxidant and anti-inflammatory properties and their possible role in the prevention and cotreatment of several chronic diseases, such as hypertension, diabetes, neurodegenerative diseases, and cancer [33-36]. In addition, polyphenols have recently attracted interest in the media and in the research community because of their potential role in reducing obesity, an increasingly serious health issue in different population age ranges $[37,38]$. Polyphenols such as catechins, anthocyanins, curcumin, and resveratrol have been suggested as exerting beneficial effects on lipid and energy metabolism [39-41] and potentially on weight status. Multiple mechanisms of action have been proposed mostly as a result of animal and cell studies, such as inhibition of the differentiation of adipocytes [40], increased fatty acid oxidation [42], decreased fatty acid synthesis, increased thermogenesis, the facilitation of energy metabolism and weight management [43], and the inhibition of digestive enzymes [44].

Phenolic compounds from tea [45], wine [29], olives $[46]$ and berries $[47,48]$ have demonstrated antimicrobial properties. Depending on their chemical structure, tea phenolics inhibit the growth of several bacterial species, such as Bacteroides spp., Clostridium spp., Escherichia coli, and Salmonella typhimurium [29]. Furthermore, tea catechins are able to change the mucin content of the ileum, affecting the bacterial adhesion and therefore their colonization [48]. Another study revealed that (+) catechin favored the growth of the Clostridium coccoides-Eubacteriumrectale group and E. coli but inhibited that of Clostridium histolyticum. In addition, the growth of beneficial bacteria, such as Bifidobacterium spp. and Lactobacillus spp., was nonaffected or even slightly favored [45, 49]. Both flavonoids and phenolic compounds reduce the adherence of Lactobacillus rhamnosus to intestinal epithelial cells [50]. The anthocyanins, a type of flavonoid, inhibit the growth of several pathogenic bacteria, including Bacillus cereus, Helicobacter pylori, Salmonella spp., and Staphylococcus spp. [47, 48]. Consequently, phytochemicals that affect the balance of the GM may influence obesity and inflammatory diseases.

Therefore, through the modulation of GM, polyphenols have the potential to generate health benefits. Although there is accumulative evidence concerning the polyphenolic effect on GM, the effects of the interaction between polyphenols and specific GM functions remain mostly uncharacterized; thus, much research remains to 
be conducted. We will focus on specific polyphenols that have been reported as able to affect GM and, in addition, influence obesity and/or inflammation.

\section{Experimental Nutritional Interventions with Phytochemicals That Modify Gut Microbiota Exert an Effect on Obesity and/or Inflammatory Parameters}

According to the United States National Agricultural Library, a "nutritional intervention" is "A clinical trial of diets or dietary supplements customized to one or more specific risk groups, such as cancer patients, pregnant women, Down syndrome children, populations with nutrient deficiencies, etc." [51]. In a broader sense, we review herein the use of phytochemicals in experimental models (mainly polyphenols), which are able to modify GM and exert an effect on obesity and/or inflammatory parameters, in order to analyze and discuss their potential use for the prophylaxis and treatment of obesity and inflammatory diseases by the maintenance and control of GM.

To compile the information from scientific literature on the polyphenols that can be related with GM, we considered the following terms for search in PubMed: "gut microbiota" OR "intestinal microbiota" OR "gut flora" OR "intestinal flora" OR "gut microflora" OR "intestinal microflora," and we added the specific compound (as listed in Figure 2). From this search, we can conclude that there is at least one report that correlates every polyphenol listed with GM. In addition, of the 40 listed compounds, there are 15 that yield at least 10 works that support the relationship between polyphenols and GM. However, there is still much work to be done in this area in terms of exploring in greater detail the specific actions of each compound on GM. Later, we added to these searches the following terms: "anti-inflammatory OR antiinflamatory" on one subsequent search, or "obesity" for another search. In both cases, the numbers of articles were scarce with a total of 116 and 71, respectively, although this number does not represent a real situation, because there are several articles that are repeated, and those that include more than one compound. From these articles, we extracted information that led to the indication of a relationship among the effects of different phytochemicals on the GM that affects obesity and/or the immune response (Table 1).

3.1. Flavonoids. The first and largest subgroup of polyphenols is integrated by flavonoids, with $>6000$ compounds identified and isolated from different plant sources [52], a large family of chemical compounds that constitutes plant and flower pigments and that shares the common function of being free radical scavengers. Due to the thousands of structurally different compounds, it becomes quite difficult to analyze all of them. Therefore, we performed a wide search of different specific compounds that have been reported in the literature and compiled them into eight subgroups, including the most representative compounds within each group (Figure 2). Essentially, all of these are widely recognized by their antioxidant $[32,53,54]$ and anti-inflammatory $[34,55,56]$ properties. Indeed, they inhibit reactive oxygen species (ROS) synthesis and hypoxia-signaling cascades, modulate cyclooxygenase 2 (COX-2), and block epidermal growth factor receptor (EGFR), insulin-like growth factor receptor-1 (IGFR-1), and nuclear factor-kappa B (NF- $\kappa$ B) signaling pathways. In addition, flavonoids are able to modulate the angiogenic process [57], and the majority of these have been recently involved with obesity $[58,59]$.

3.1.1. Flavones. Numerous studies have been undertaken on the influence of GM on the intestinal absorption and metabolism of particular flavones, such as apigenin, luteolin, and chrysin, both in rodents and in human cells [60-63]. On the other hand, there are multiple studies that associate different flavones with anti-inflammatory effects. This is the case for apigenin [64-67], luteolin [68, 69], and chrysin [34]. Furthermore, recent studies involve apigenin with the amelioration of obesity-related inflammation [70] and regulating lipid and glucose metabolism [71], luteolin with the amelioration of obesity-associated insulin resistance, hepatic steatosis and fat-diet-induced cognitive deficits [72-75], and chrysin, which inhibits peroxisome proliferator-activated receptor $-\gamma(\mathrm{PPAR}-\gamma)$ and CCAAT/enhancer binding protein $\mathrm{A}(\mathrm{C} / \mathrm{EBP} \alpha)$, major adipogenic transcription factors in preadipocytes [75] and which also modulate enhanced lipid metabolism [76]. However, to the best of our knowledge, there is still no study that considers together these following three aspects: GM, inflammation, and obesity as positively affected by these flavones. Consequently, this constitutes a whole new avenue for studying these interactions.

3.1.2. Flavanones. Like the previous subgroup, flavanones also influence and interact with GM $[28,77,78]$. The main compounds included here also exhibit anti-inflammatory properties, such as hesperetin [79, 80], naringenin [81], morin [82-84], and eriodictyol [85-87]. Additionally, they influence lipid metabolism as a potential preventive strategy for obesity. For instance, hesperetin exhibits lipid-lowering efficacy [88, 89]; naringenin regulates lipid and glucose metabolism [71] and also prevents hepatic steatosis and glucose intolerance [90] by suppressing macrophage infiltration into the adipose tissue [91]. In addition, both compounds improve membrane lipid composition [92]. Furthermore, morin exhibits antihyperlipidemic potential by reducing lipid accumulation [31, 93]. Finally, eriodictyol ameliorates lipid disorders and suppresses lipogenesis [94]. Taken together, all of this evidence strongly indicates that these compounds can be usefully applied to prevent or treat obesity and its associated inflammation, but it is relevant to take GM into account in order to incorporate it into the organism's metabolism. Again, there are to our knowledge no studies that correlate all three of these aspects.

3.1.3. Flavonones. In this case, nomenclature represents a problem in the literature search, because the term "flavonones" is usually substituted by "flavanones," which in fact represent a different subgroup. Due to this, compounds included in this subgroup were individually searched in databases. Three compounds were considered: hesperidin, 


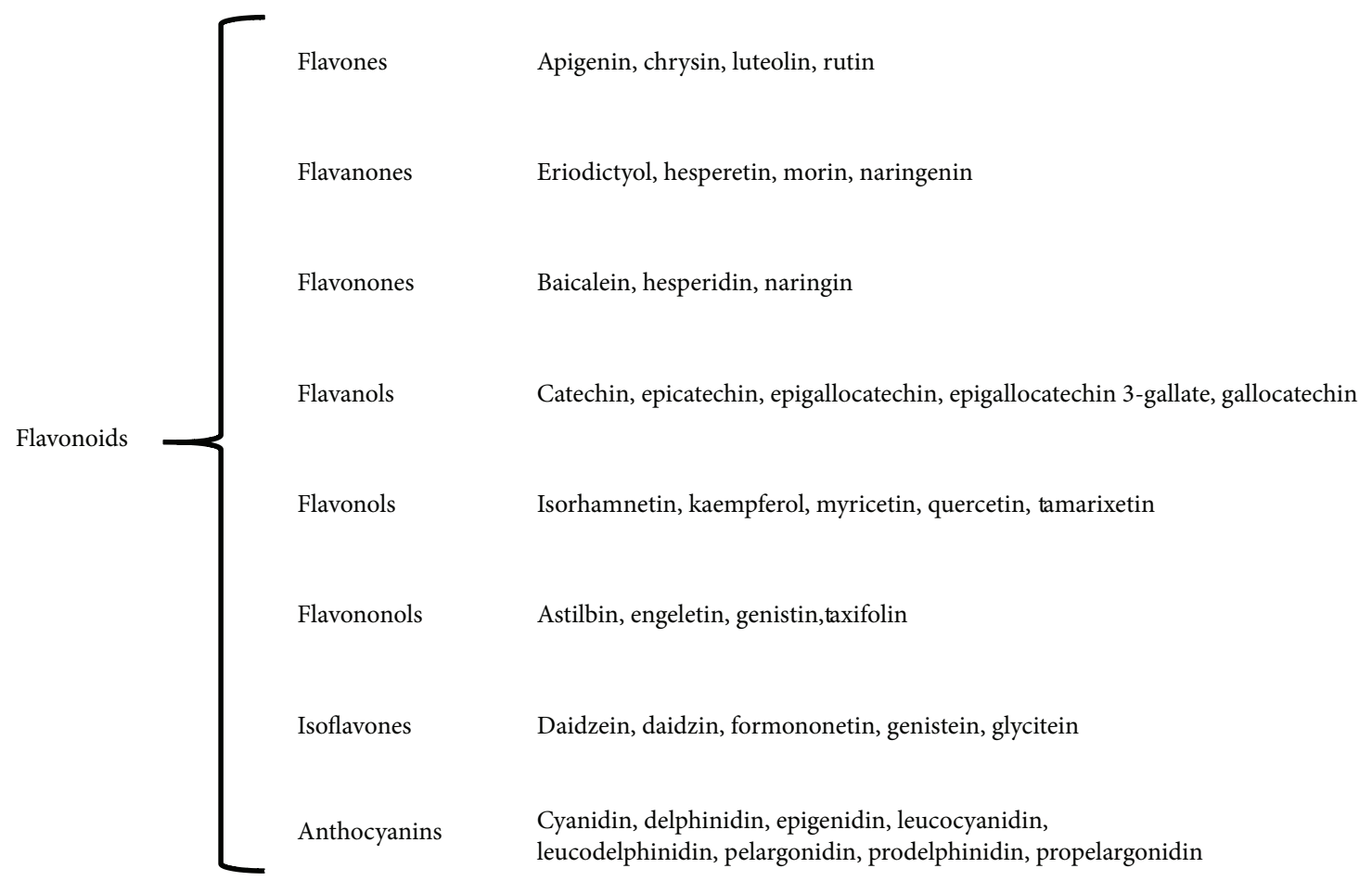

FIGURE 2: Classification of the eight foremost flavonoid subgroups.

naringin, and baicalein. In fact, the former two can be confused with similarly named compounds from the flavanone subgroup (see above) but constitute different compounds. As for all the polyphenols, the latter is metabolized by the GM $[93,95]$ and exhibits strong anti-inflammatory properties $[79,96,97]$. Additionally, these compounds also influence lipid metabolism as follows: hesperidin improves lipid metabolism against alcohol injury by reducing endoplasmic reticulum stress and DNA damage [98] and exhibits an antiobesity effect [99]; naringin also influences the lipid profile and ameliorates obesity [100], and finally, baicalein regulates early adipogenesis by inhibiting lipid accumulation and $\mathrm{m}$-TOR signaling [101]. Again, there is a need for studies that take into account the following elements together, that is, GM metabolism of the polyphenols and their specific effect on lipid metabolism, obesity, and inflammation.

3.1.4. Flavanols. This subgroup mainly comprises catechins, which are more abundant in the skin of fruits than in fruit pulp. Catechins found in cranberries may contribute to cancer prevention [102]. Catechins are abundant in green tea, to which has been attributed several beneficial impacts on health. Traditionally, green tea has been used to improve resistance to disease and to eliminate alcohol and toxins by clearing the urine and improve blood flow [103, 104]. Lately, emerging areas of interest have been the effects of green tea for the prevention of cancer and cardiovascular diseases, as well as their effects on angiogenesis, inflammation, and oxidation $[105,106]$.

This subgroup of flavonoids is one of the few that has been studied to date under the lens of their relationship with GM and their anti-inflammatory actions [107], as well as their role in lipid metabolism and obesity [105, 108]. Among the compounds included in this group, we find the following: catechin, epicatechin, epigallocatechin, epigallocatechin 3gallate, and gallocatechin. Practically, all of these have already begun to be studied in the light of their relationship between GM and inflammation, as well as that related with lipid metabolism and obesity (see Table 1 for specific examples). However, much work remains to ascertain the mechanisms by which these compounds are able to benefit health.

3.1.5. Flavonols. Compounds in this subgroup have also been studied as related with GM and inflammation or obesity, mainly quercetin and kaempferol, while another three, rutin, myricetin, and isohamnetin, have not to our knowledge been studied within this context. Quercetin protects against highfat diet-induced fatty liver disease by modulating GM imbalance and attenuating inflammation [109]. Kaempferol also exhibits protective properties, both anti-inflammatory and antioxidant, in adipocytes in response to proinflammatory stimuli [110]. These two works, by Porras et al., and Le Sage et al., respectively, constitute some clear examples of the experimental approximations that need to be done to increase our knowledge on the relationships already mentioned among phytochemicals, GM, inflammation, and obesity. Therefore, this subgroup constitutes that of the leading compounds in the study of the relationship among these three elements (Figure 3).

3.1.6. Flavononols. This is another subgroup with nomenclature problems for the literature search, because the term "flavononols" is usually substituted by "flavonols," which is a different group (see above). For this reason, compounds 


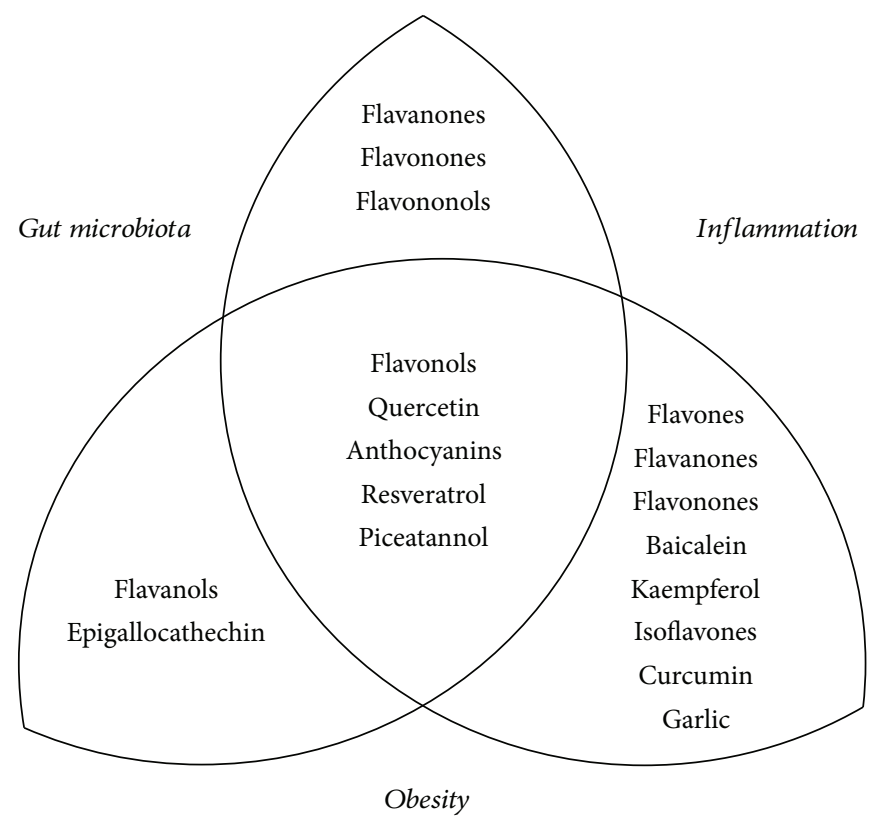

Figure 3: Phytochemicals that affect gut microbiota with anti-inflammatory and/or antiobesity properties.

included in this group were individually searched. This subgroup includes genistein, taxifolin, engeletin, and astilbin. Again, all of these are metabolized by GM and also exhibit potent anti-inflammatory properties [111-114], as well as being able to influence energy metabolism (both lipid and carbohydrate) [115-117]. Despite this, to our knowledge there is a lack of research regarding the possible effects of this subgroup of flavonoids on obesity and/or inflammation through their effect on GM.

3.1.7. Isoflavones. This subgroup has been partially studied with relation to GM and inflammation or obesity. It is made up of phytoestrogens, which are mainly present in soybeans. Isoflavones are metabolized by GM $[30,118,119]$. They also show an anti-inflammatory effect [120], as well as having had a hypocholesterolemic effect attributed to them [121]. The following are found included in this group: daidzein, genistein, glycitein, formononetin, and daidzin. Daidzein is metabolized by GM mainly into equol, which contributes to the beneficial effects of soybeans [122]; thus, it is relevant that dietary fat intake diminishes GM's ability to synthesize equol [123]. In addition, daidzein and genistein reduced lipid peroxidation in vivo and increased the resistance of lowdensity lipoproteins (LDL) to oxidation [124] and both exhibit an anti-inflammatory activity [125]. Glycitein affects gene expression in adipose tissue [126] and demonstrates antiobese and antidiabetic effects [127]. Additionally, together with daidzein and genistein, glycitein exhibits an anti-inflammatory and neuroprotective effect on microglial cells [128]. Finally, formononetin and daidzin have also received attention because of their anti-inflammatory properties [129-131]. Once again, this group would be interesting for further studies regarding their metabolism by GM in relation with inflammation and lipid metabolism for obesity.
3.1.8. Anthocyanins. Anthocyanins are a class of flavonoids that are ubiquitously found in fruits and vegetables and they possess many pharmacological properties, for example, lipid-lowering, antioxidant, antiallergic, anti-inflammatory, antimicrobial, anticarcinogenic, and antidiabetic actions [132-135]. Strawberries constitute a source of anthocyanins and have been recently broadly evaluated for their effect on human health, due to their rich phytochemical content, effectiveness in rodent models, and almost no toxicity observed in pilot studies in humans [136, 137]. In rodent models, for example, strawberries have shown anticancer activity in several tissues [138]. This subgroup includes a long list of compounds, such as cyanidin, delphinidin, epigenidin, leucocyanidin, leucodelphinidin, pelargonidin, prodelphinidin, and propelargonidin. Although there are fewer than 70 papers that correlate at least one of these compounds with anti-inflammatory activity or obesity (or lipid metabolism), there are only a dozen papers, to our knowledge, which correlate any of these compounds with their metabolism by $\mathrm{GM}$, and none of them associate this information among these aspects. Therefore, this constitutes a nearly complete virgin area still to be explored.

\subsection{Phenolic Acids}

3.2.1. Curcumin. A second subgroup of polyphenols is constituted by phenolic acids, such as curcumin (diferuloylmethane), which is abundantly present in the rhizomes of the Curcuma longa, used both in traditional medicine and in cooking. Curcumin has been used for the coadjuvant treatment of a large diversity of diseases, including hepatic disorders, respiratory conditions, and inflammation and also obesity, diabetes, rheumatism, and even certain tumors. One relevant aspect to notice is that even at very high doses, no studies in animals or humans have revealed significant 
curcumin toxicity [139]. Curcumin possesses a great protective impact on acute alcoholic liver injury in mice and can improve the antioxidant activity of mice after acute administration of alcohol. It can increase the activity of antioxidant enzymes in liver tissues [140]. Curcumin is also metabolized by GM; the biotransformation of turmeric curcuminoids by human GM is reminiscent of equol production from the soybean isoflavone daidzein [141]. Curcumin modulates GM during colitis and colon cancer [142] and improves intestinal barrier function [141]. In addition, it is largely considered a potent anti-inflammatory and neuroprotective agent $[143,144]$, as well as a possible factor for the treatment of obesity [145-147]. The research on curcumin is extensive; notwithstanding, there are still very few papers that deal with the relationship of curcumin metabolism by GM, its action over intestinal permeability, and effect on obesity and/or inflammation (Table 1).

\subsection{Stilbenes}

3.3.1. Resveratrol. The third subgroup of polyphenols comprises stilbenoids, such as resveratrol (3,5,4'-trihydroxystilbene) and piceatannol (3,3',4,5'-trans-trihydroxystilbene). Resveratrol is a natural, nonflavonoid polyphenolic compound that can be found in grape wines, grape skins (red wine), pines, peanuts, mulberries, cranberries, and legumes, among other plant species, which synthesize it in response to stress or against pathogen invasion [148, 149]. Resveratrol is studied as a potent antioxidant with neuroprotective activity. Several in vitro and in vivo studies show various properties for resveratrol as a potent antioxidant and antiaging molecule, which also exhibits anti-inflammatory, cardioprotective, and anticancer effects, able to promote vascular endothelial function and enhance lipid metabolism $[147,150]$. Principally, it is the anti-inflammatory effect of resveratrol which has been widely reported [151], as well as its antiobesity effect [152]. Regarding the GM effect, resveratrol favored the proliferation of Bifidobacterium and Lactobacillus and counteracts the virulence factors of Proteus mirabilis [29]. In fact, resveratrol exhibits pleiotropic actions, modulates transcription factor NF- $\kappa \mathrm{B}$, and inhibits the cytochrome P450 isoenzyme CYP1 A1, as well as suppressing the expression and activity of cyclooxygenase enzymes, modulating p53, cyclins, and various phosphodiesterases, suppressing proinflammatory molecules, and inhibiting the expression of hypoxia-inducible transcription factor 1 (HIF-1 $\alpha$ ) and vascular endothelial growth factor (VEGF), among other actions [153]. Some studies analyze the effect of resveratrol on GM combined with their anti-inflammatory and antiobesity actions (Table 1). It constitutes a good example of the potential that the profound study of phytochemicals and their impact on health represents.

3.3.2. Piceatannol. Piceatannol is a hydroxylated analogue of resveratrol found in various plants (mainly grapes and white tea). It is less studied than resveratrol but also exhibits a wide biological activity [154]. It mainly exhibits potent anticancer properties and also antioxidant and anti-inflammatory activities, which make it a potentially useful nutraceutical and possibly an attractive biomolecule for pharmacological use [59]. Recently, Hijona et al. [155] studied its beneficial effects on obesity. Although these are limited, it constitutes a promissory phytochemical molecule.

\subsection{Organosulfur Compounds}

3.4.1. Garlic. In addition to polyphenols, another group of phytochemicals of relevance for health is the organosulfur compounds. For instance, garlic (Allium sativum) is a rich source of organosulfur compounds and exhibits a plethora of beneficial effects against microbial infections as well as cardioprotective, anticarcinogenic, and anti-inflammatory activity [156].

Nearly $80 \%$ of garlic's cysteine sulfoxide is constituted by alliin (allylcysteine sulfoxide). When raw or crushed garlic is chopped, the "allinase" enzyme is released which catalyzes sulfonic acid formation from cysteine sulfoxides and when the two react with each other, they produce an unstable compound: thiosulfinate or allicin. The in vitro breakdown of allicin produces numerous fat-soluble components: diallyl sulfide; DiAllylDiSulfide (DADS), and DiAllylTriSulfide (DATS). Likewise, vinyldithiins, S-allylcysteine, ajoene, S-1prpenylcysteine, and S-allylmercaptocysteine are important constituents of garlic powder, oil, and extracts [157, 158].

Naturally occurring products have attracted the attention of researchers as sources of novel drugs and drug leads for the treatment of obesity [159-161]. Allium species have been used in herbolary or traditional medicine for the treatment of metabolic diseases, and Allium-derived extracts have recently become of interest for their antiobesity effects [162].

The chemical constituents of garlic are enzymes (asalliinase) and organosulfur compounds (such as alliin and its derived agent, allicin). The effect of garlic on different medical conditions (such as hypertension, hyperlipidemia, diabetes mellitus, rheumatic disease, the common cold, arteriosclerosis, and cancer) has been widely investigated. Garlic is known as a hypolipidemic agent because of its role in increasing the hydrolysis of triacylglycerols due to increased lipase activity [163]. Moreover, garlic reduces the biosynthesis of triacylglycerols through its blocking of nicotinamide adenine dinucleotide phosphate. On the other hand, garlic contains abundant antioxidants and can induce antioxidant enzymes [164]. Thus, garlic is a potential hepatoprotective agent against liver disorders [165]. Experimental studies have shown that garlic and its organosulfur compounds might reduce alcohol-related liver enzymes, glutathione reductase, alkaline phosphatase, lactate dehydrogenase, and alcohol dehydrogenase, as well as enhance liver antioxidant enzymes, and alleviate hepatic-fat accumulation [165-172]. However, there has been no clinical trial on patients with liver disorders [164].

\section{Concluding Remarks and Perspectives}

Several issues need to be solved before natural products can be effectively translated into the clinic. With regard to the best source of bioactive molecules or compounds, the following aspects should be considered: (a) if they are better 
acquired directly from food in the diet or from pharmacological sources (purified or through synthetic analogues) and (b) if they should be used alone or as a cotreatment in combination with approved drugs. Therefore, there is a need to develop specific clinical trials. Disadvantages of commercial nutraceutic preparations include the high variability in formulations (preparation methods and chemical composition), as well as the dosage quantification and the different means of administration. Research devoted to the optimization of phytochemical formulation and dosage has become of critical importance. Given the low bioavailability of phytochemicals, the development of more useful synthetic derivatives has become a great concern [173].

Once nutrients and nutraceuticals have been incorporated into the body, the gut environment is essential in maintaining homeostasis; in this sense, like GM, the surface of the intestinal mucous membrane plays a fundamental role in the preservation of homeostasis. Consequently, the correct functioning of its permeability is of great importance [174]. Several pathologies, as well as susceptibility to metabolic diseases, have been linked to alterations in the permeability of the intestinal barrier. Humans possess two interacting genomes: their own and that of their host microbiome, the majority of which resides in the gut, in the layer of mucin glycoproteins (mucus) produced by the cells called goblet cells [168]. The microbiome provides products such as vitamins and nutrients to host cells, thereby establishing a beneficial ecosystem for host physiology and preventing the arrival of pathogens [175]. Thus, a symbiotic relationship is established between both genomes, through the expression of pattern recognition receptors (PRRs) for the sense of the presence of intestinal microbiota, through the microbe-associated molecular patterns (MAMPs). This communication between the two genomes results in the accuracy of the mucosal barrier function, by regulating the production of its components: mucus, antimicrobial peptides, IgA and IL-22, facilitating homeostasis, and immune tolerance [175-177]. Therefore, GM and the human host influence each other by exchanging their metabolic active molecules [178], working together, as a hologenome, to maintain mutual health [179].

Another current challenge is convincing a skeptical health sector of the use of such compounds as medicines, or at least in conjunction with pharmaceutical medicines, which could serve both practitioners and patients better [180]. For instance, research on traditional Chinese medicine has substantially increased recently through the search for its molecular, cellular, and pharmacological bases, with the identification of active substances and the investigation of mechanisms of action [181]. Although the available cumulative data strongly suggest the positive effects of a large variety of phytochemicals in terms of health, it remains insufficient in order to directly extract solid conclusions, due mainly to the lack of confirmation, in human trials, of the results obtained by the animal model studies. Consequently, more research must be focused on the analysis of different phenolic compounds metabolized by GM and their influence on human health [182]. Results are crucial for the precise understanding of the influence of GM on the metabolism of micronutrients and phytochemicals within the human organism, and their metabolism undergone upon ingestion, in order to correctly attribute beneficial health properties to specific polyphenols with a more complete knowledge of their bioavailability, metabolism, and effects on carbohydrate and lipid metabolism, and therefore their use in treating obesity and inflammatory diseases.

\section{Conflicts of Interest}

The authors declare that the research was conducted in the absence of any commercial or financial relationships that could be construed as a potential conflict of interest.

\section{Authors' Contributions}

Lucrecia Carrera-Quintanar and Rocío I. López Roa contributed equally to this work.

\section{Acknowledgments}

The work was partially supported by Universidad de Guadalajara Grant PRO-SNI 2017 to Daniel OrtuñoSahagún and SEP-UDG-CA-454 to Barbara Vizmanos and Lucrecia Carrera-Quintanar and CONACyT-México Grant CB-2015-256736 to Rocío I. López Roa. Fellowship support was provided by CONACyT-México Grant 622462 to Marina A. Sánchez-Sánchez.

\section{References}

[1] E. J. Gallagher, D. Leroith, and E. Karnieli, "The metabolic syndrome-from insulin resistance to obesity and diabetes," Medical Clinics of North America, vol. 95, no. 5, pp. 855-873, 2011.

[2] J. J. Guerrero-Garcia, L. Carrera-Quintanar, R. I. Lopez-Roa, A. L. Marquez-Aguirre, A. E. Rojas-Mayorquin, and D. Ortuno-Sahagun, "Multiple sclerosis and obesity: possible roles of adipokines," Mediators of Inflammation, vol. 2016, Article ID 4036232, 24 pages, 2016.

[3] D. K. Dahiya, P. M. Renuka, U. K. Shandilya et al., "Gut microbiota modulation and its relationship with obesity using prebiotic fibers and probiotics: a review," Frontiers in Microbiology, vol. 8, p. 563, 2017.

[4] F. Del Chierico, P. Vernocchi, L. Bonizzi et al., "Early-life gut microbiota under physiological and pathological conditions: the central role of combined meta-omics-based approaches," Journal of Proteomics, vol. 75, no. 15, pp. 4580-4587, 2012.

[5] J. C. Clemente, L. K. Ursell, L. W. Parfrey, and R. Knight, "The impact of the gut microbiota on human health: an integrative view," Cell, vol. 148, no. 6, pp. 1258-1270, 2012.

[6] C. C. Smith, L. K. Snowberg, J. Gregory Caporaso, R. Knight, and D. I. Bolnick, "Dietary input of microbes and host genetic variation shape among-population differences in stickleback gut microbiota," The ISME Journal, vol. 9, no. 11, pp. 2515-2526, 2015.

[7] C. Leung, L. Rivera, J. B. Furness, and P. W. Angus, "The role of the gut microbiota in NAFLD," Nature Reviews Gastroenterology \& Hepatology, vol. 13, no. 7, pp. 412-425, 2016.

[8] E. Perez-Chanona and G. Trinchieri, "The role of microbiota in cancer therapy," Current Opinion in Immunology, vol. 39, pp. 75-81, 2016. 
[9] C. T. Peterson, V. Sharma, L. Elmen, and S. N. Peterson, "Immune homeostasis, dysbiosis and therapeutic modulation of the gut microbiota," Clinical \& Experimental Immunology, vol. 179, no. 3, pp. 363-377, 2015.

[10] R. Medzhitov, "Toll-like receptors and innate immunity," Nature Reviews Immunology, vol. 1, no. 2, pp. 135-145, 2001.

[11] F. Fava and S. Danese, "Intestinal microbiota in inflammatory bowel disease: friend of foe?," The World Journal of Gastroenterology, vol. 17, no. 5, pp. 557-566, 2011.

[12] M. B. Roberfroid, "Prebiotics and probiotics: are they functional foods?," The American Journal of Clinical Nutrition, vol. 71, no. 6, Supplement, pp. 1682S-1687S, 2000.

[13] D. Ortuno Sahagun, A. L. Marquez-Aguirre, S. QuinteroFabian, R. I. Lopez-Roa, and A. E. Rojas-Mayorquin, "Modulation of PPAR- $\gamma$ by nutraceutics as complementary treatment for obesity-related disorders and inflammatory diseases," PPAR Research, vol. 2012, Article ID 318613, 17 pages, 2012.

[14] R. G. Kok, A. de Waal, F. Schut, G. W. Welling, G. Weenk, and K. J. Hellingwerf, "Specific detection and analysis of a probiotic bifidobacterium strain in infant feces," Applied and Environmental Microbiology, vol. 62, no. 10, pp. 3668-3672, 1996.

[15] R. E. Ley, C. A. Lozupone, M. Hamady, R. Knight, and J. I. Gordon, "Worlds within worlds: evolution of the vertebrate gut microbiota," Nature Reviews Microbiology, vol. 6, no. 10, pp. 776-788, 2008.

[16] G. D. Wu, J. Chen, C. Hoffmann et al., "Linking long-term dietary patterns with gut microbial enterotypes," Science, vol. 334, no. 6052, pp. 105-108, 2011.

[17] K. A. Pyra, D. C. Saha, and R. A. Reimer, "Prebiotic fiber increases hepatic acetyl CoA carboxylase phosphorylation and suppresses glucose-dependent insulinotropic polypeptide secretion more effectively when used with metformin in obese rats," The Journal of Nutrition, vol. 142, no. 2, pp. 213-220, 2012.

[18] J. M. Laparra and Y. Sanz, "Interactions of gut microbiota with functional food components and nutraceuticals," Pharmacological Research, vol. 61, no. 3, pp. 219-225, 2010.

[19] H. M. Eid, M. L. Wright, N. V. Anil Kumar et al., "Significance of microbiota in obesity and metabolic diseases and the modulatory potential by medicinal plant and food ingredients," Frontiers in Pharmacology, vol. 8, p. 387, 2017.

[20] K. P. Scott, S. W. Gratz, P. O. Sheridan, H. J. Flint, and S. H. Duncan, "The influence of diet on the gut microbiota," Pharmacological Research, vol. 69, no. 1, pp. 52-60, 2013.

[21] R. H. Liu, "Potential synergy of phytochemicals in cancer prevention: mechanism of action," The Journal of Nutrition, vol. 134, no. 12, pp. 3479S-3485S, 2004.

[22] J. Schrezenmeir and M. de Vrese, "Probiotics, prebiotics, and synbiotics-approaching a definition," The American Journal of Clinical Nutrition, vol. 73, no. 2, pp. 361s-364s, 2001.

[23] A. T. Vieira, C. Fukumori, and C. M. Ferreira, "New insights into therapeutic strategies for gut microbiota modulation in inflammatory diseases," Clinical \& Translational Immunology, vol. 5, no. 6, article e87, 2016.

[24] A. Scalbert, I. T. Johnson, and M. Saltmarsh, "Polyphenols: antioxidants and beyond," The American Journal of Clinical Nutrition, vol. 81, no. 1, pp. 215S-217S, 2005.

[25] F. A. Tomas-Barberan, M. V. Selma, and J. C. Espin, "Interactions of gut microbiota with dietary polyphenols and consequences to human health," Current Opinion in Clinical Nutrition and Metabolic Care, vol. 19, no. 6, pp. 471-476, 2016.

[26] M. Kim, J. Lee, and J. Han, "Deglycosylation of isoflavone Cglycosides by newly isolated human intestinal bacteria," Journal of the Science of Food and Agriculture, vol. 95, no. 9, pp. 1925-1931, 2015.

[27] U. Lewandowska, K. Szewczyk, E. Hrabec, A. Janecka, and S. Gorlach, "Overview of metabolism and bioavailability enhancement of polyphenols," Journal of Agricultural and Food Chemistry, vol. 61, no. 50, pp. 12183-12199, 2013.

[28] J. F. Stevens and C. S. Maier, "The chemistry of gut microbial metabolism of polyphenols," Phytochemistry Reviews, vol. 15, no. 3, pp. 425-444, 2016.

[29] M. Larrosa, C. Luceri, E. Vivoli et al., "Polyphenol metabolites from colonic microbiota exert anti-inflammatory activity on different inflammation models," Molecular Nutrition \& Food Research, vol. 53, no. 8, pp. 1044-1054, 2009.

[30] E. Bowey, H. Adlercreutz, and I. Rowland, "Metabolism of isoflavones and lignans by the gut microflora: a study in germ-free and human flora associated rats," Food and Chemical Toxicology, vol. 41, no. 5, pp. 631-636, 2003.

[31] A. Duda-Chodak, "The inhibitory effect of polyphenols on human gut microbiota," Journal of Physiology and Pharmacology, vol. 63, no. 5, pp. 497-503, 2012.

[32] K. B. Pandey and S. I. Rizvi, "Plant polyphenols as dietary antioxidants in human health and disease," Oxidative Medicine and Cellular Longevity, vol. 2, no. 5, 278 pages, 2009.

[33] A. Medina-Remon, R. Casas, A. Tressserra-Rimbau et al., "Polyphenol intake from a Mediterranean diet decreases inflammatory biomarkers related to atherosclerosis: a substudy of the PREDIMED trial," British Journal of Clinical Pharmacology, vol. 83, no. 1, pp. 114-128, 2017.

[34] M. Zeinali, S. A. Rezaee, and H. Hosseinzadeh, "An overview on immunoregulatory and anti-inflammatory properties of chrysin and flavonoids substances," Biomedicine \& Pharmacotherapy, vol. 92, pp. 998-1009, 2017.

[35] R. Conte, V. Marturano, G. Peluso, A. Calarco, and P. Cerruti, "Recent advances in nanoparticle-mediated delivery of anti-inflammatory phytocompounds," International Journal of Molecular Sciences, vol. 18, no. 4, p. 709, 2017.

[36] D. P. Xu, Y. Li, X. Meng et al., "Natural antioxidants in foods and medicinal plants: extraction, assessment and resources," International Journal of Molecular Sciences, vol. 18, no. 1, p. 96, 2017.

[37] Y. Kim, J. B. Keogh, and P. M. Clifton, "Polyphenols and glycemic control," Nutrients, vol. 8, no. 1, 17 pages, 2016.

[38] M. J. Amiot, C. Riva, and A. Vinet, "Effects of dietary polyphenols on metabolic syndrome features in humans: a systematic review," Obesity Reviews, vol. 17, no. 7, pp. 573-586, 2016.

[39] M. Meydani and S. T. Hasan, "Dietary polyphenols and obesity," Nutrients, vol. 2, no. 7, pp. 737-751, 2010.

[40] S. Y. Min, H. Yang, S. G. Seo et al., "Cocoa polyphenols suppress adipogenesis in vitro and obesity in vivo by targeting insulin receptor," International Journal of Obesity, vol. 37, no. 4, pp. 584-592, 2013.

[41] A. B. Kunnumakkara, D. Bordoloi, G. Padmavathi et al., "Curcumin, the golden nutraceutical: multitargeting for multiple chronic diseases," British Journal of Pharmacology, vol. 174, no. 11, pp. 1325-1348, 2017. 
[42] H. Shimoda, J. Tanaka, M. Kikuchi et al., "Effect of polyphenol-rich extract from walnut on diet-induced hypertriglyceridemia in mice via enhancement of fatty acid oxidation in the liver," Journal of Agricultural and Food Chemistry, vol. 57, no. 5, pp. 1786-1792, 2009.

[43] S. J. Stohs and V. Badmaev, "A review of natural stimulant and non-stimulant thermogenic agents," Phytotherapy Research, vol. 30, no. 5, pp. 732-740, 2016.

[44] Y. Gu, W. J. Hurst, D. A. Stuart, and J. D. Lambert, "Inhibition of key digestive enzymes by cocoa extracts and procyanidins," Journal of Agricultural and Food Chemistry, vol. 59, no. 10, pp. 5305-5311, 2011.

[45] H. C. Lee, A. M. Jenner, C. S. Low, and Y. K. Lee, "Effect of tea phenolics and their aromatic fecal bacterial metabolites on intestinal microbiota," Research in Microbiology, vol. 157, no. 9, pp. 876-884, 2006.

[46] E. Medina, A. García, C. Romero, A. De Castro, and M. Brenes, "Study of the anti-lactic acid bacteria compounds in table olives," International Journal of Food Science \& Technology, vol. 44, no. 7, pp. 1286-1291, 2009.

[47] L. J. Nohynek, H. L. Alakomi, M. P. Kähkönen et al., "Berry phenolics: antimicrobial properties and mechanisms of action against severe human pathogens," Nutrition and Cancer, vol. 54, no. 1, pp. 18-32, 2006.

[48] R. Puupponen-Pimia, L. Nohynek, S. Hartmann-Schmidlin et al., "Berry phenolics selectively inhibit the growth of intestinal pathogens," Journal of Applied Microbiology, vol. 98, no. 4, pp. 991-1000, 2005.

[49] X. Tzounis, J. Vulevic, G. G. Kuhnle et al., "Flavanol monomer-induced changes to the human faecal microflora," The British Journal of Nutrition, vol. 99, no. 4, pp. 782-792, 2008.

[50] S. G. Parkar, D. E. Stevenson, and M. A. Skinner, "The potential influence of fruit polyphenols on colonic microflora and human gut health," International Journal of Food Microbiology, vol. 124, no. 3, pp. 295-298, 2008.

[51] N. A. L. f. United States Department of Agriculture, "Defenition: nutritional intervention," 2017, https://definedterm .com/nutritional_intervention.

[52] S. Kumar and A. K. Pandey, "Chemistry and biological activities of flavonoids: an overview," The Scientific World Journal, vol. 2013, Article ID 162750, 16 pages, 2013.

[53] G. Agati, E. Azzarello, S. Pollastri, and M. Tattini, "Flavonoids as antioxidants in plants: location and functional significance," Plant Science, vol. 196, pp. 67-76, 2012.

[54] G. B. Bubols, R. Vianna Dda, A. Medina-Remon et al., "The antioxidant activity of coumarins and flavonoids," Mini Reviews in Medicinal Chemistry, vol. 13, no. 3, pp. 318-334, 2013.

[55] L. Marzocchella, M. Fantini, M. Benvenuto et al., "Dietary flavonoids: molecular mechanisms of action as anti- inflammatory agents," Recent Patents on Inflammation \& Allergy Drug Discovery, vol. 5, no. 3, pp. 200-220, 2011.

[56] M. Antunes-Ricardo, J. Gutierrez-Uribe, and S. O. SernaSaldivar, "Anti-inflammatory glycosylated flavonoids as therapeutic agents for treatment of diabetes-impaired wounds," Current Topics in Medicinal Chemistry, vol. 15, no. 23, pp. 2456-2463, 2015.

[57] M. E. van Meeteren, J. J. Hendriks, C. D. Dijkstra, and E. A. van Tol, "Dietary compounds prevent oxidative damage and nitric oxide production by cells involved in demyelinating disease," Biochemical Pharmacology, vol. 67, no. 5, pp. 967-975, 2004.

[58] R. T. Hurt and T. Wilson, "Geriatric obesity: evaluating the evidence for the use of flavonoids to promote weight loss," Journal of Nutrition in Gerontology and Geriatrics, vol. 31, no. 3, pp. 269-289, 2012.

[59] M. Kawser Hossain, A. Abdal Dayem, J. Han et al., "Molecular mechanisms of the anti-obesity and anti-diabetic properties of flavonoids," International Journal of Molecular Sciences, vol. 17, no. 4, p. 569, 2016.

[60] A. L. Simons, M. Renouf, S. Hendrich, and P. A. Murphy, "Human gut microbial degradation of flavonoids: structure-function relationships," Journal of Agricultural and Food Chemistry, vol. 53, no. 10, pp. 4258-4263, 2005.

[61] L. Hanske, G. Loh, S. Sczesny, M. Blaut, and A. Braune, "The bioavailability of apigenin-7-glucoside is influenced by human intestinal microbiota in rats," The Journal of Nutrition, vol. 139, no. 6, pp. 1095-1102, 2009.

[62] A. Braune and M. Blaut, "Deglycosylation of puerarin and other aromatic C-glucosides by a newly isolated human intestinal bacterium," Environmental Microbiology, vol. 13, no. 2, pp. 482-494, 2011.

[63] D. Angelino, M. Berhow, P. Ninfali, and E. H. Jeffery, "Caecal absorption of vitexin-2-O-xyloside and its aglycone apigenin, in the rat," Food \& Function, vol. 4, no. 9, pp. 1339-1345, 2013.

[64] J. H. Lee, H. Y. Zhou, S. Y. Cho, Y. S. Kim, Y. S. Lee, and C. S. Jeong, "Anti-inflammatory mechanisms of apigenin: inhibition of cyclooxygenase-2 expression, adhesion of monocytes to human umbilical vein endothelial cells, and expression of cellular adhesion molecules," Archives of Pharmacal Research, vol. 30, no. 10, pp. 1318-1327, 2007.

[65] M. Karamese, H. S. Erol, M. Albayrak, G. Findik Guvendi, E. Aydin, and S. Aksak Karamese, "Anti-oxidant and antiinflammatory effects of apigenin in a rat model of sepsis: an immunological, biochemical, and histopathological study," Immunopharmacology and Immunotoxicology, vol. 38, no. 3, pp. 228-237, 2016.

[66] J. A. Lee, S. K. Ha, E. Cho, and I. Choi, "Resveratrol as a bioenhancer to improve anti-inflammatory activities of apigenin," Nutrients, vol. 7, no. 11, pp. 9650-9661, 2015.

[67] C. Mascaraque, R. Gonzalez, M. D. Suarez, A. Zarzuelo, F. Sanchez de Medina, and O. Martinez-Augustin, "Intestinal anti-inflammatory activity of apigenin $\mathrm{K}$ in two rat colitis models induced by trinitrobenzenesulfonic acid and dextran sulphate sodium," The British Journal of Nutrition, vol. 113, no. 04 , pp. 618-626, 2015.

[68] G. Seelinger, I. Merfort, and C. M. Schempp, "Anti-oxidant, anti-inflammatory and anti-allergic activities of luteolin," Planta Medica, vol. 74, no. 14, pp. 1667-1677, 2008.

[69] S. F. Nabavi, N. Braidy, O. Gortzi et al., "Luteolin as an antiinflammatory and neuroprotective agent: a brief review," Brain Research Bulletin, vol. 119, Part A, pp. 1-11, 2015.

[70] X. Feng, D. Weng, F. Zhou et al., "Activation of PPAR $\gamma$ by a natural flavonoid modulator, apigenin ameliorates obesity-related inflammation via regulation of macrophage polarization," eBioMedicine, vol. 9, pp. 61-76, 2016.

[71] B. Ren, W. Qin, F. Wu et al., "Apigenin and naringenin regulate glucose and lipid metabolism, and ameliorate vascular dysfunction in type 2 diabetic rats," European Journal of Pharmacology, vol. 773, pp. 13-23, 2016. 
[72] X. Zhang, Y. Yang, Z. Wu, and P. Weng, "The modulatory effect of anthocyanins from purple sweet potato on human intestinal microbiota in vitro," Journal of Agricultural and Food Chemistry, vol. 64, no. 12, pp. 2582-2590, 2016.

[73] E. Y. Kwon, U. J. Jung, T. Park, J. W. Yun, and M. S. Choi, "Luteolin attenuates hepatic steatosis and insulin resistance through the interplay between the liver and adipose tissue in mice with diet-induced obesity," Diabetes, vol. 64, no. 5, pp. 1658-1669, 2015.

[74] Y. Liu, X. Fu, N. Lan et al., "Luteolin protects against high fat diet-induced cognitive deficits in obesity mice," Behavioural Brain Research, vol. 267, pp. 178-188, 2014.

[75] N. Xu, L. Zhang, J. Dong et al., "Low-dose diet supplement of a natural flavonoid, luteolin, ameliorates diet-induced obesity and insulin resistance in mice," Molecular Nutrition \& Food Research, vol. 58, no. 6, pp. 1258-1268, 2014.

[76] J. H. Choi and J. W. Yun, "Chrysin induces brown fat-like phenotype and enhances lipid metabolism in 3T3-L1 adipocytes," Nutrition, vol. 32, no. 9, pp. 1002-1010, 2016.

[77] W. Lin, W. Wang, H. Yang, D. Wang, and W. Ling, "Influence of intestinal microbiota on the catabolism of flavonoids in mice," Journal of Food Science, vol. 81, no. 12, pp. H3026H3034, 2016.

[78] A. Braune and M. Blaut, "Bacterial species involved in the conversion of dietary flavonoids in the human gut," Gut Microbes, vol. 7, no. 3, pp. 216-234, 2016.

[79] Q. Q. Wang, J. B. Shi, C. Chen, C. Huang, W. J. Tang, and J. Li, "Hesperetin derivatives: synthesis and antiinflammatory activity," Bioorganic \& Medicinal Chemistry Letters, vol. 26, no. 5, pp. 1460-1465, 2016.

[80] H. Parhiz, A. Roohbakhsh, F. Soltani, R. Rezaee, and M. Iranshahi, "Antioxidant and anti-inflammatory properties of the citrus flavonoids hesperidin and hesperetin: an updated review of their molecular mechanisms and experimental models," Phytotherapy Research, vol. 29, no. 3, pp. 323-331, 2015.

[81] M. F. Manchope, R. Casagrande, and W. A. Verri Jr., "Naringenin: an analgesic and anti-inflammatory citrus flavanone," Oncotarget, vol. 8, no. 3, pp. 3766-3767, 2017.

[82] K. M. Lee, Y. Lee, H. J. Chun et al., "Neuroprotective and anti-inflammatory effects of morin in a murine model of Parkinson's disease," Journal of Neuroscience Research, vol. 94, no. 10, pp. 865-878, 2016.

[83] S. Franova, I. Kazimierova, L. Pappova, M. Joskova, L. Plank, and M. Sutovska, "Bronchodilatory, antitussive and antiinflammatory effect of morin in the setting of experimentally induced allergic asthma," The Journal of Pharmacy and Pharmacology, vol. 68, no. 8, pp. 1064-1072, 2016.

[84] Y. Zhou, Z. Q. Cao, H. Y. Wang et al., "The antiinflammatory effects of Morin hydrate in atherosclerosis is associated with autophagy induction through cAMP signaling," Molecular Nutrition \& Food Research, vol. 61, no. 9, article 1600966, 2017.

[85] I. Mokdad-Bzeouich, N. Mustapha, A. Sassi et al., "Investigation of immunomodulatory and anti-inflammatory effects of eriodictyol through its cellular anti-oxidant activity," Cell Stress and Chaperones, vol. 21, no. 5, pp. 773-781, 2016.

[86] J. K. Lee, "Anti-inflammatory effects of eriodictyol in lipopolysaccharidestimulated raw 264.7 murine macrophages," Archives of Pharmacal Research, vol. 34, no. 4, pp. 671-679, 2011.
[87] G. F. Zhu, H. J. Guo, Y. Huang, C. T. Wu, and X. F. Zhang, "Eriodictyol, a plant flavonoid, attenuates LPS-induced acute lung injury through its antioxidative and anti-inflammatory activity," Experimental and Therapeutic Medicine, vol. 10, no. 6, pp. 2259-2266, 2015.

[88] H. K. Kim, T. S. Jeong, M. K. Lee, Y. B. Park, and M. S. Choi, "Lipid-lowering efficacy of hesperetin metabolites in highcholesterol fed rats," Clinica Chimica Acta, vol. 327, no. 1-2, pp. 129-137, 2003.

[89] G. S. Choi, S. Lee, T. S. Jeong et al., "Evaluation of hesperetin 7-O-lauryl ether as lipid-lowering agent in high-cholesterolfed rats," Bioorganic \& Medicinal Chemistry, vol. 12, no. 13, pp. 3599-3605, 2004.

[90] J. M. Assini, E. E. Mulvihill, A. C. Burke et al., "Naringenin prevents obesity, hepatic steatosis, and glucose intolerance in male mice independent of fibroblast growth factor 21," Endocrinology, vol. 156, no. 6, pp. 2087-2102, 2015.

[91] H. Yoshida, H. Watanabe, A. Ishida et al., "Naringenin suppresses macrophage infiltration into adipose tissue in an early phase of high-fat diet-induced obesity," Biochemical and Biophysical Research Communications, vol. 454, no. 1, pp. 95-101, 2014.

[92] M. Miler, J. Živanović, V. Ajdžanović et al., "Citrus flavanones naringenin and hesperetin improve antioxidant status and membrane lipid compositions in the liver of old-aged Wistar rats," Experimental Gerontology, vol. 84, pp. 49-60, 2016.

[93] P. Prahalathan, M. Saravanakumar, and B. Raja, "The flavonoid morin restores blood pressure and lipid metabolism in DOCA-salt hypertensive rats," Redox Report, vol. 17, no. 4, pp. 167-175, 2012.

[94] X. Wang, D. M. Zhang, T. T. Gu et al., "Morin reduces hepatic inflammation-associated lipid accumulation in high fructose-fed rats via inhibiting sphingosine kinase 1/sphingosine 1-phosphate signaling pathway," Biochemical Pharmacology, vol. 86, no. 12, pp. 1791-1804, 2013.

[95] D. H. Kim, E. A. Jung, I. S. Sohng, J. A. Han, T. H. Kim, and M. J. Han, "Intestinal bacterial metabolism of flavonoids and its relation to some biological activities," Archives of Pharmacal Research, vol. 21, no. 1, pp. 17-23, 1998.

[96] S. Bharti, N. Rani, B. Krishnamurthy, and D. S. Arya, "Preclinical evidence for the pharmacological actions of naringin: a review," Planta Medica, vol. 80, no. 6, pp. 437-451, 2014.

[97] B. Dinda, S. Dinda, S. DasSharma, R. Banik, A. Chakraborty, and M. Dinda, "Therapeutic potentials of baicalin and its aglycone, baicalein against inflammatory disorders," European Journal of Medicinal Chemistry, vol. 131, pp. 68-80, 2017.

[98] Z. Zhou, W. Zhong, H. Lin et al., "Hesperidin protects against acute alcoholic injury through improving lipid metabolism and cell damage in zebrafish larvae," Evidence-based Complementary and Alternative Medicine, vol. 2017, Article ID 7282653, 9 pages, 2017.

[99] T. Ohara, K. Muroyama, Y. Yamamoto, and S. Murosaki, "Oral intake of a combination of glucosyl hesperidin and caffeine elicits an anti-obesity effect in healthy, moderately obese subjects: a randomized double-blind placebocontrolled trial," Nutrition Journal, vol. 15, p. 6, 2016.

[100] M. A. Alam, K. Kauter, and L. Brown, "Naringin improves diet-induced cardiovascular dysfunction and obesity in high carbohydrate, high fat diet-fed rats," Nutrients, vol. 5, no. 3, pp. 637-650, 2013. 
[101] M. J. Seo, H. S. Choi, H. J. Jeon, M. S. Woo, and B. Y. Lee, "Baicalein inhibits lipid accumulation by regulating early adipogenesis and m-TOR signaling," Food and Chemical Toxicology, vol. 67, pp. 57-64, 2014.

[102] S. J. Duthie, A. M. Jenkinson, A. Crozier et al., "The effects of cranberry juice consumption on antioxidant status and biomarkers relating to heart disease and cancer in healthy human volunteers," European Journal of Nutrition, vol. 45, no. 2, pp. 113-122, 2006.

[103] M. Rameshrad, B. M. Razavi, and H. Hosseinzadeh, "Protective effects of green tea and its main constituents against natural and chemical toxins: a comprehensive review," Food and Chemical Toxicology, vol. 100, pp. 115-137, 2017.

[104] L. Chen, H. Mo, L. Zhao et al., "Therapeutic properties of green tea against environmental insults," The Journal of Nutritional Biochemistry, vol. 40, pp. 1-13, 2017.

[105] P. L. Janssens, R. Hursel, and M. S. Westerterp-Plantenga, "Nutraceuticals for body-weight management: the role of green tea catechins," Physiology \& Behavior, vol. 162, pp. 83-87, 2016.

[106] F. Thielecke and M. Boschmann, "The potential role of green tea catechins in the prevention of the metabolic syndrome - a review," Phytochemistry, vol. 70, no. 1, pp. 11-24, 2009.

[107] F. Y. Fan, L. X. Sang, and M. Jiang, "Catechins and their therapeutic benefits to inflammatory bowel disease," Molecules, vol. 22 , no. 3, p. 484, 2017.

[108] R. Hursel and M. S. Westerterp-Plantenga, "Catechin- and caffeine-rich teas for control of body weight in humans," The American Journal of Clinical Nutrition, vol. 98, no. 6, pp. 1682S-1693S, 2013.

[109] D. Porras, E. Nistal, S. Martinez-Florez et al., "Protective effect of quercetin on high-fat diet-induced non-alcoholic fatty liver disease in mice is mediated by modulating intestinal microbiota imbalance and related gut-liver axis activation," Free Radical Biology and Medicine, vol. 102, pp. 188-202, 2017.

[110] F. Le Sage, O. Meilhac, and M. P. Gonthier, "Anti-inflammatory and antioxidant effects of polyphenols extracted from Antirhea borbonica medicinal plant on adipocytes exposed to Porphyromonas gingivalis and Escherichia coli lipopolysaccharides," Pharmacological Research, vol. 119, pp. 303-312, 2017.

[111] J. W. Jeong, H. H. Lee, M. H. Han, G. Y. Kim, W. J. Kim, and Y. H. Choi, "Anti-inflammatory effects of genistein via suppression of the toll-like receptor 4-mediated signaling pathway in lipopolysaccharide-stimulated BV2 microglia," Chemico-Biological Interactions, vol. 212, pp. 30-39, 2014.

[112] M. B. Gupta, T. N. Bhalla, G. P. Gupta, C. R. Mitra, and K. P. Bhargava, "Anti-inflammatory activity of taxifolin," Japanese Journal of Pharmacology, vol. 21, no. 3, pp. 377-382, 1971.

[113] H. Huang, Z. Cheng, H. Shi, W. Xin, T. T. Wang, and L. L. $\mathrm{Yu}$, "Isolation and characterization of two flavonoids, engeletin and astilbin, from the leaves of Engelhardia roxburghiana and their potential anti-inflammatory properties," Journal of Agricultural and Food Chemistry, vol. 59, no. 9, pp. 45624569, 2011.

[114] C. L. Lu, Y. F. Zhu, M. M. Hu et al., "Optimization of astilbin extraction from the rhizome of Smilax glabra, and evaluation of its anti-inflammatory effect and probable underlying mechanism in lipopolysaccharide-induced RAW264.7 macrophages," Molecules, vol. 20, no. 1, pp. 625-644, 2015.
[115] J. Cao, R. Echelberger, M. Liu et al., "Soy but not bisphenol A (BPA) or the phytoestrogen genistin alters developmental weight gain and food intake in pregnant rats and their offspring," Reproductive Toxicology, vol. 58, pp. 282-294, 2015.

[116] S. Pisonero-Vaquero, M. V. Garcia-Mediavilla, F. Jorquera et al., "Modulation of PI3K-LXR $\alpha$-dependent lipogenesis mediated by oxidative/nitrosative stress contributes to inhibition of HCV replication by quercetin," Laboratory Investigation; a Journal of Technical Methods and Pathology, vol. 94, no. 3, pp. 262-274, 2014.

[117] H. Haraguchi, Y. Mochida, S. Sakai et al., "Protection against oxidative damage by dihydroflavonols in Engelhardtia chrysolepis," Bioscience, Biotechnology, and Biochemistry, vol. 60, no. 6, pp. 945-948, 1996.

[118] N. J. Turner, B. M. Thomson, and I. C. Shaw, "Bioactive isoflavones in functional foods: the importance of gut microflora on bioavailability," Nutrition Reviews, vol. 61, no. 6, pp. 204213, 2003.

[119] J. P. Yuan, J. H. Wang, and X. Liu, "Metabolism of dietary soy isoflavones to equol by human intestinal microflora - implications for health," Molecular Nutrition \& Food Research, vol. 51, no. 7, pp. 765-781, 2007.

[120] J. S. Park, M. S. Woo, D. H. Kim et al., "Antiinflammatory mechanisms of isoflavone metabolites in lipopolysaccharide-stimulated microglial cells," The Journal of Pharmacology and Experimental Therapeutics, vol. 320, no. 3, pp. 1237-1245, 2007.

[121] D. D. Ramdath, E. M. Padhi, S. Sarfaraz, S. Renwick, and A. M. Duncan, "Beyond the cholesterol-lowering effect of soy protein: a review of the effects of dietary soy and its constituents on risk factors for cardiovascular disease," Nutrients, vol. 9, no. 4, p. 324, 2017.

[122] E. J. Reverri, C. M. Slupsky, D. O. Mishchuk, and F. M. Steinberg, "Metabolomics reveals differences between three daidzein metabolizing phenotypes in adults with cardiometabolic risk factors," Molecular Nutrition \& Food Research, vol. 61, no. 1, article 1600132, 2017.

[123] I. R. Rowland, H. Wiseman, T. A. Sanders, H. Adlercreutz, and E. A. Bowey, "Interindividual variation in metabolism of soy isoflavones and lignans: influence of habitual diet on equol production by the gut microflora," Nutrition and Cancer, vol. 36, no. 1, pp. 27-32, 2000.

[124] H. Wiseman, J. D. O'Reilly, H. Adlercreutz et al., "Isoflavone phytoestrogens consumed in soy decrease F2-isoprostane concentrations and increase resistance of low-density lipoprotein to oxidation in humans," The American Journal of Clinical Nutrition, vol. 72, no. 2, pp. 395-400, 2000.

[125] M. Hämäläinen, R. Nieminen, P. Vuorela, M. Heinonen, and E. Moilanen, "Anti-inflammatory effects of flavonoids: genistein, kaempferol, quercetin, and daidzein inhibit STAT-1 and $\mathrm{NF}-\kappa \mathrm{B}$ activations, whereas flavone, isorhamnetin, naringenin, and pelargonidin inhibit only NF- $\kappa \mathrm{B}$ activation along with their inhibitory effect on iNOS expression and NO production in activated macrophages," Mediators of Inflammation, vol. 2007, Article ID 45673, 10 pages, 2007.

[126] V. van der Velpen, A. Geelen, P. C. Hollman, E. G. Schouten, P. van 't Veer, and L. A. Afman, "Isoflavone supplement composition and equol producer status affect gene expression in adipose tissue: a double-blind, randomized, placebocontrolled crossover trial in postmenopausal women," The American Journal of Clinical Nutrition, vol. 100, no. 5, pp. 1269-1277, 2014. 
[127] Y. Zang, K. Igarashi, and C. Yu, "Anti-obese and anti-diabetic effects of a mixture of daidzin and glycitin on C57BL/6J mice fed with a high-fat diet," Bioscience, Biotechnology, and Biochemistry, vol. 79, no. 1, pp. 117-123, 2015.

[128] F. Marotta, G. S. Mao, T. Liu et al., "Anti-inflammatory and neuroprotective effect of a phytoestrogen compound on rat microglia," Annals of the New York Academy of Sciences, vol. 1089, no. 1, pp. 276-281, 2006.

[129] R. Lima Cavendish, J. de Souza Santos, R. Belo Neto et al., "Antinociceptive and anti-inflammatory effects of Brazilian red propolis extract and formononetin in rodents," Journal of Ethnopharmacology, vol. 173, pp. 127-133, 2015.

[130] Z. Ma, W. Ji, Q. Fu, and S. Ma, "Formononetin inhibited the inflammation of LPS-induced acute lung injury in mice associated with induction of PPAR gamma expression," Inflammation, vol. 36, no. 6, pp. 1560-1566, 2013.

[131] S. E. Jin, Y. K. Son, B. S. Min, H. A. Jung, and J. S. Choi, “Antiinflammatory and antioxidant activities of constituents isolated from Pueraria lobata roots," Archives of Pharmacal Research, vol. 35, no. 5, pp. 823-837, 2012.

[132] J. He and M. M. Giusti, "Anthocyanins: natural colorants with health-promoting properties," Annual Review of Food Science and Technology, vol. 1, no. 1, pp. 163-187, 2010.

[133] S. Vendrame and D. Klimis-Zacas, "Anti-inflammatory effect of anthocyanins via modulation of nuclear factor- $\kappa \mathrm{B}$ and mitogen-activated protein kinase signaling cascades," Nutrition Reviews, vol. 73, no. 6, pp. 348-358, 2015.

[134] H. Guo and W. Ling, "The update of anthocyanins on obesity and type 2 diabetes: experimental evidence and clinical perspectives," Reviews in Endocrine and Metabolic Disorders, vol. 16, no. 1, pp. 1-13, 2015.

[135] S. Asgary, M. Rafieian-Kopaei, F. Shamsi, S. Najafi, and A. Sahebkar, "Biochemical and histopathological study of the anti-hyperglycemic and anti-hyperlipidemic effects of cornelian cherry (Cornus mas L.) in alloxan-induced diabetic rats," Journal of Complementary and Integrative Medicine, vol. 11, no. 2, pp. 63-69, 2014.

[136] A. Basu, A. Nguyen, N. M. Betts, and T. J. Lyons, "Strawberry as a functional food: an evidence-based review," Critical Reviews in Food Science and Nutrition, vol. 54, no. 6, pp. 790-806, 2014.

[137] F. Giampieri, S. Tulipani, J. M. Alvarez-Suarez, J. L. Quiles, B. Mezzetti, and M. Battino, "The strawberry: composition, nutritional quality, and impact on human health," Nutrition, vol. 28, no. 1, pp. 9-19, 2012.

[138] N. Shi, S. K. Clinton, Z. Liu et al., "Strawberry phytochemicals inhibit azoxymethane/dextran sodium sulfate-induced colorectal carcinogenesis in Crj: CD-1 mice," Nutrients, vol. 7, no. 3, pp. 1696-1715, 2015.

[139] E. Talero, J. Avila-Roman, and V. Motilva, "Chemoprevention with phytonutrients and microalgae products in chronic inflammation and colon cancer," Current Pharmaceutical Design, vol. 18, no. 26, pp. 3939-3965, 2012.

[140] Y. Zeng, J. Liu, Z. Huang, X. Pan, and L. Zhang, "Effect of curcumin on antioxidant function in the mice with acute alcoholic liver injury," Wei Sheng Yan Jiu, vol. 43, no. 2, pp. 282-285, 2014.

[141] S. Burapan, M. Kim, and J. Han, "Curcuminoid demethylation as an alternative metabolism by human intestinal microbiota," Journal of Agricultural and Food Chemistry, vol. 65, no. 16, pp. 3305-3310, 2017.
[142] R. M. McFadden, C. B. Larmonier, K. W. Shehab et al., "The role of curcumin in modulating colonic microbiota during colitis and colon cancer prevention," Inflammatory Bowel Diseases, vol. 21, no. 11, pp. 2483-2494, 2015.

[143] F. Ullah, A. Liang, A. Rangel, E. Gyengesi, G. Niedermayer, and G. Munch, "High bioavailability curcumin: an antiinflammatory and neurosupportive bioactive nutrient for neurodegenerative diseases characterized by chronic neuroinflammation," Archives of Toxicology, vol. 91, no. 4, pp. 1623-1634, 2017.

[144] Y. Tizabi, L. L. Hurley, Z. Qualls, and L. Akinfiresoye, "Relevance of the anti-inflammatory properties of curcumin in neurodegenerative diseases and depression," Molecules, vol. 19, no. 12, pp. 20864-20879, 2014.

[145] A. Shehzad, T. Ha, F. Subhan, and Y. S. Lee, "New mechanisms and the anti-inflammatory role of curcumin in obesity and obesity-related metabolic diseases," European Journal of Nutrition, vol. 50, no. 3, pp. 151-161, 2011.

[146] B. B. Aggarwal, "Targeting inflammation-induced obesity and metabolic diseases by curcumin and other nutraceuticals," Annual Review of Nutrition, vol. 30, no. 1, pp. 173199, 2010.

[147] P. G. Bradford, “Curcumin and obesity,” BioFactors, vol. 39, no. 1, pp. 78-87, 2013.

[148] B. Catalgol, S. Batirel, Y. Taga, and N. K. Ozer, "Resveratrol: French paradox revisited," Frontiers in Pharmacology, vol. 3, p. 141, 2012.

[149] B. C. Vastano, Y. Chen, N. Zhu, C. T. Ho, Z. Zhou, and R. T. Rosen, "Isolation and identification of stilbenes in two varieties of Polygonum cuspidatum," Journal of Agricultural and Food Chemistry, vol. 48, no. 2, pp. 253-256, 2000.

[150] J. Gambini, M. Inglés, G. Olaso et al., "Properties of resveratrol: in vitro and in vivo studies about metabolism, bioavailability, and biological effects in animal models and humans," Oxidative Medicine and Cellular Longevity, vol. 2015, Article ID 837042, 13 pages, 2015.

[151] A. Malhotra, S. Bath, and F. Elbarbry, "An organ system approach to explore the antioxidative, anti-inflammatory, and cytoprotective actions of resveratrol," Oxidative Medicine and Cellular Longevity, vol. 2015, Article ID 803971, 15 pages, 2015.

[152] L. Aguirre, A. Fernandez-Quintela, N. Arias, and M. P. Portillo, "Resveratrol: anti-obesity mechanisms of action," Molecules, vol. 19, no. 11, pp. 18632-18655, 2014.

[153] G. T. Diaz-Gerevini, G. Repossi, A. Dain, M. C. Tarres, U. N. Das, and A. R. Eynard, "Beneficial action of resveratrol: how and why?," Nutrition, vol. 32, no. 2, pp. 174-178, 2016.

[154] H. Piotrowska, M. Kucinska, and M. Murias, "Biological activity of piceatannol: leaving the shadow of resveratrol," Mutation Research/Reviews in Mutation Research, vol. 750, no. 1, pp. 60-82, 2012.

[155] E. Hijona, L. Aguirre, P. Pérez-Matute et al., "Limited beneficial effects of piceatannol supplementation on obesity complications in the obese Zucker rat: gut microbiota, metabolic, endocrine, and cardiac aspects," Journal of Physiology and Biochemistry, vol. 72, no. 3, pp. 567-582, 2016.

[156] R. Arreola, S. Quintero-Fabián, R. I. López-Roa et al., "Immunomodulation and anti-inflammatory effects of garlic compounds," Journal of Immunology Research, vol. 2015, Article ID 401630, 13 pages, 2015. 
[157] H. Amagase, B. L. Petesch, H. Matsuura, S. Kasuga, and Y. Itakura, "Intake of garlic and its bioactive components," The Journal of Nutrition, vol. 131, no. 3, pp. 955S-962S, 2001.

[158] M. S. Butt, A. Naz, M. T. Sultan, and M. M. Qayyum, “Antioncogenic perspectives of spices/herbs: a comprehensive review," EXCLI Journal, vol. 12, pp. 1043-1065, 2013.

[159] D. J. Newman and G. M. Cragg, "Natural products as sources of new drugs over the last 25 years," Journal of Natural Products, vol. 70, no. 3, pp. 461-477, 2007.

[160] T. Sergent, J. Vanderstraeten, J. Winand, P. Beguin, and Y.-J. Schneider, "Phenolic compounds and plant extracts as potential natural anti-obesity substances," Food Chemistry, vol. 135, no. 1, pp. 68-73, 2012.

[161] J. W. Yun, "Possible anti-obesity therapeutics from nature - a review," Phytochemistry, vol. 71, no. 14-15, pp. 1625-1641, 2010.

[162] M. H. Yang, N. H. Kim, J. D. Heo et al., "Comparative evaluation of sulfur compounds contents and antiobesity properties of Allium hookeri prepared by different drying methods," Evidence-Based Complementary and Alternative Medicine, vol. 2017, Article ID 2436927, 10 pages, 2017.

[163] G. Aviello, L. Abenavoli, F. Borrelli et al., "Garlic: empiricism or science?," Natural Product Communications, vol. 4, no. 12, pp. 1785-1796, 2009.

[164] Z. Ghorbani, M. Hajizadeh, and A. Hekmatdoost, "Dietary supplementation in patients with alcoholic liver disease: a review on current evidence," Hepatobiliary \& Pancreatic Diseases International, vol. 15, no. 4, pp. 348-360, 2016.

[165] R. Raghu, C. T. Liu, M. H. Tsai et al., "Transcriptome analysis of garlic-induced hepatoprotection against alcoholic fatty liver," Journal of Agricultural and Food Chemistry, vol. 60, no. 44, pp. 11104-11119, 2012.

[166] T. Zeng, F. F. Guo, C. L. Zhang et al., "The anti-fatty liver effects of garlic oil on acute ethanol-exposed mice," Chemico-Biological Interactions, vol. 176, no. 2-3, pp. 234-242, 2008.

[167] T. Zeng and K. Q. Xie, "Could garlic partially-counteract excess alcohol consumption? A postulated role of garlic oil in prevention of ethanol-induced hepatotoxicity," Medical Hypotheses, vol. 71, no. 6, pp. 984-985, 2008.

[168] T. Zeng, C. L. Zhang, F. Y. Song, X. L. Zhao, and K. Q. Xie, "Garlic oil alleviated ethanol-induced fat accumulation via modulation of SREBP-1, PPAR- $\alpha$, and CYP2E1," Food and Chemical Toxicology, vol. 50, no. 3-4, pp. 485-491, 2012.

[169] G. I. Adoga, "Effect of garlic oil extract on glutathione reductase levels in rats fed on high sucrose and alcohol diets: a possible mechanism of the activity of the oil," Bioscience Reports, vol. 6, no. 10, pp. 909-912, 1986.

[170] G. I. Adoga, "The mechanism of the hypolipidemic effect of garlic oil extract in rats fed on high sucrose and alcohol diets," Biochemical and Biophysical Research Communications, vol. 142, no. 3, pp. 1046-1052, 1987.

[171] G. I. Adoga and J. Osuji, "Effect of garlic oil extract on serum, liver and kidney enzymes of rats fed on high sucrose and alcohol diets," Biochemistry International, vol. 13, no. 4, pp. 615-624, 1986.

[172] M. H. Kim, M. J. Kim, J. H. Lee et al., "Hepatoprotective effect of aged black garlic on chronic alcohol-induced liver injury in rats," Journal of Medicinal Food, vol. 14, no. 7-8, pp. 732-738, 2011.
[173] L. Morbidelli, "Polyphenol-based nutraceuticals for the control of angiogenesis: analysis of the critical issues for human use," Pharmacological Research, vol. 111, pp. 384-393, 2016.

[174] M. Spiljar, D. Merkler, and M. Trajkovski, “The immune system bridges the gut microbiota with systemic energy homeostasis: focus on TLRs, mucosal barrier, and SCFAs," Frontiers in Immunology, vol. 8, p. 1353, 2017.

[175] E. M. Brown, M. Sadarangani, and B. B. Finlay, "The role of the immune system in governing host-microbe interactions in the intestine," Nature Immunology, vol. 14, no. 7, pp. 660-667, 2013.

[176] F. A. Carvalho, J. D. Aitken, M. Vijay-Kumar, and A. T. Gewirtz, "Toll-like receptor-gut microbiota interactions: perturb at your own risk!," Annual Review of Physiology, vol. 74, no. 1, pp. 177-198, 2012.

[177] O. Takeuchi and S. Akira, "Pattern recognition receptors and inflammation," Cell, vol. 140, no. 6, pp. 805-820, 2010.

[178] L. V. Hooper, T. Midtvedt, and J. I. Gordon, "How hostmicrobial interactions shape the nutrient environment of the mammalian intestine," Annual Review of Nutrition, vol. 22, no. 1, pp. 283-307, 2002.

[179] L. Zhao and J. Shen, "Whole-body systems approaches for gut microbiota-targeted, preventive healthcare," Journal of Biotechnology, vol. 149, no. 3, pp. 183-190, 2010.

[180] F. Chen, Q. Wen, J. Jiang et al., "Could the gut microbiota reconcile the oral bioavailability conundrum of traditional herbs?," Journal of Ethnopharmacology, vol. 179, pp. 253264, 2016.

[181] J. L. Tang, "Research priorities in traditional Chinese medicine," BMJ, vol. 333, no. 7564, pp. 391-394, 2006.

[182] J. I. Mosele, A. Macia, and M. J. Motilva, "Metabolic and microbial modulation of the large intestine ecosystem by non-absorbed diet phenolic compounds: a review," Molecules, vol. 20, no. 9, pp. 17429-17468, 2015.

[183] E. Päivärinta, M. Niku, J. Maukonen et al., "Changes in intestinal immunity, gut microbiota, and expression of energy metabolism-related genes explain adenoma growth in bilberry and cloudberry-fed Apc ${ }^{\mathrm{Min}}$ mice," Nutrition Research, vol. 36, no. 11, pp. 1285-1297, 2016.

[184] P. Pu, X. A. Wang, M. Salim et al., "Baicalein, a natural product, selectively activating AMPK $\alpha_{2}$ and ameliorates metabolic disorder in diet-induced mice," Molecular and Cellular Endocrinology, vol. 362, no. 1-2, pp. 128-138, 2012.

[185] M. Remely, F. Ferk, S. Sterneder et al., "EGCG prevents high fat diet-induced changes in gut microbiota, decreases of DNA strand breaks, and changes in expression and DNA methylation of Dnmt1 and MLH1 in C57BL/6J male mice," Oxidative Medicine and Cellular Longevity, vol. 2017, Article ID 3079148, 17 pages, 2017.

[186] M. Cheng, X. Zhang, Y. Miao, J. Cao, Z. Wu, and P. Weng, "The modulatory effect of (-)-epigallocatechin 3-O-(3-Omethyl) gallate (EGCG3"Me) on intestinal microbiota of high fat diet-induced obesity mice model," Food Research International, vol. 92, pp. 9-16, 2017.

[187] T. Unno, M. Sakuma, and S. Mitsuhashi, "Effect of dietary supplementation of (-)-epigallocatechin gallate on gut microbiota and biomarkers of colonic fermentation in rats," Journal of Nutritional Science and Vitaminology, vol. 60, no. 3, pp. 213-219, 2014.

[188] U. Etxeberria, N. Arias, N. Boqué et al., "Reshaping faecal gut microbiota composition by the intake of trans-resveratrol 
and quercetin in high-fat sucrose diet-fed rats," The Journal of Nutritional Biochemistry, vol. 26, no. 6, pp. 651-660, 2015.

[189] E. Roldán-Marín, B. N. Krath, M. Poulsen et al., "Effects of an onion by-product on bioactivity and safety markers in healthy rats," The British Journal of Nutrition, vol. 102, no. 11, pp. 1574-1582, 2009.

[190] D. Esposito, T. Damsud, M. Wilson et al., "Black currant anthocyanins attenuate weight gain and improve glucose metabolism in diet-induced obese mice with intact, but not disrupted, gut microbiome," Journal of Agricultural and Food Chemistry, vol. 63, no. 27, pp. 6172-6180, 2015.

[191] T. Wu, Q. Tang, Z. Yu et al., "Inhibitory effects of sweet cherry anthocyanins on the obesity development in C57BL/ 6 mice," International Journal of Food Sciences and Nutrition, vol. 65, no. 3, pp. 351-359, 2014.

[192] A. M. Neyrinck, M. Alligier, P. B. Memvanga et al., "Curcuma longa extract associated with white pepper lessens high fat diet-induced inflammation in subcutaneous adipose tissue," PLoS One, vol. 8, no. 11, article e81252, 2013.

[193] S. S. Ghosh, J. Bie, J. Wang, and S. Ghosh, "Oral supplementation with non-absorbable antibiotics or curcumin attenuates western diet-induced atherosclerosis and glucose intolerance in LDLR-/- mice - role of intestinal permeability and macrophage activation," PLoS One, vol. 9, no. 9, article e108577, 2014.

[194] J. Wang, S. S. Ghosh, and S. Ghosh, "Curcumin improves intestinal barrier function: modulation of intracellular signaling, and organization of tight junctions," American Journal of Physiology Cell Physiology, vol. 312, no. 4, pp. C438-C445, 2017.

[195] Y. Qiao, J. Sun, S. Xia, X. Tang, Y. Shi, and G. Le, "Effects of resveratrol on gut microbiota and fat storage in a mouse model with high-fat-induced obesity," Food \& Function, vol. 5, no. 6, pp. 1241-1249, 2014.

[196] T. M. Dao, A. Waget, P. Klopp et al., "Resveratrol increases glucose induced GLP-1 secretion in mice: a mechanism which contributes to the glycemic control," PLoS One, vol. 6, no. 6, article e20700, 2011.

[197] M. K. Nøhr, T. P. Kroager, K. W. Sanggaard et al., "SILACMS based characterization of LPS and resveratrol induced changes in adipocyte proteomics - resveratrol as ameliorating factor on LPS induced changes," PLoS One, vol. 11, no. 7, article e0159747, 2016.

[198] A. S. Korsholm, T. N. Kjaer, M. J. Ornstrup, and S. B. Pedersen, "Comprehensive metabolomic analysis in blood, urine, fat, and muscle in men with metabolic syndrome: a randomized, placebo-controlled clinical trial on the effects of resveratrol after four months' treatment," International Journal of Molecular Sciences, vol. 18, no. 3, p. 554, 2017.

[199] Y. C. Tung, Y. H. Lin, H. J. Chen et al., "Piceatannol exerts anti-obesity effects in C57BL/6 mice through modulating adipogenic proteins and gut microbiota," Molecules, vol. 21, no. 11, p. 1419, 2016.

[200] Y. S. Lai, W. C. Chen, C. T. Ho et al., "Garlic essential oil protects against obesity-triggered nonalcoholic fatty liver disease through modulation of lipid metabolism and oxidative stress," Journal of Agricultural and Food Chemistry, vol. 62, no. 25, pp. 5897-5906, 2014. 


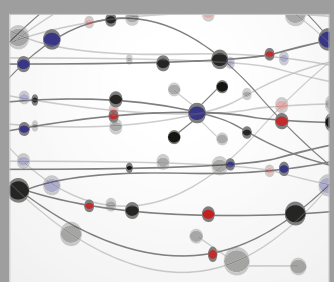

The Scientific World Journal
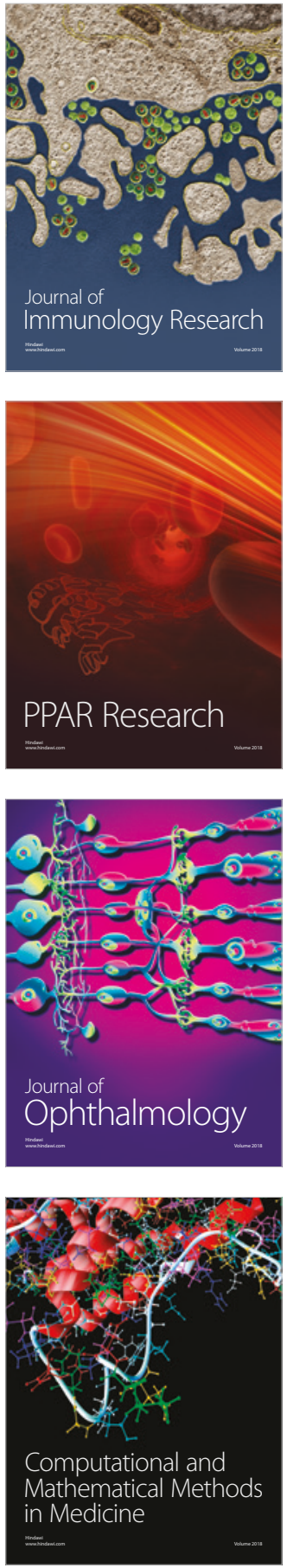

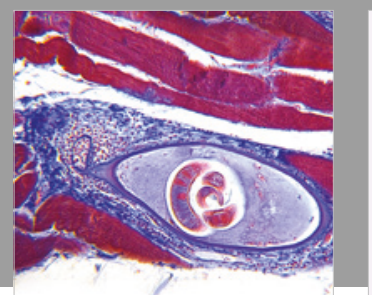

Gastroenterology Research and Practice

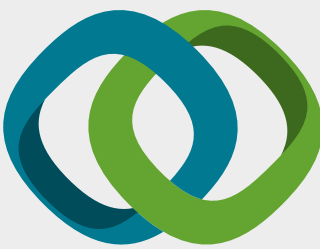

\section{Hindawi}

Submit your manuscripts at

www.hindawi.com
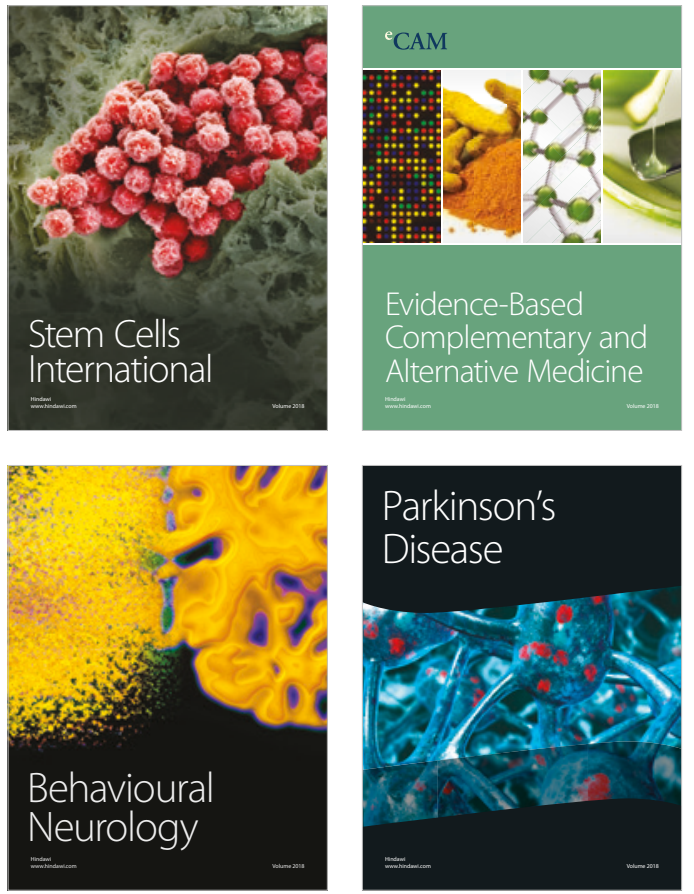

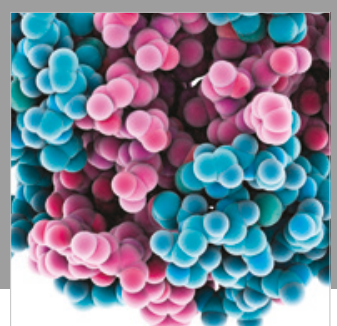

ournal of

Diabetes Research

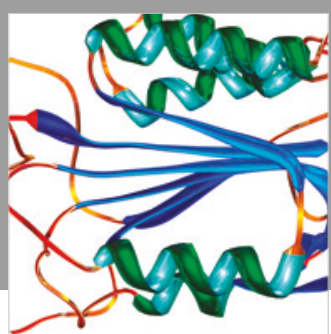

Disease Markers
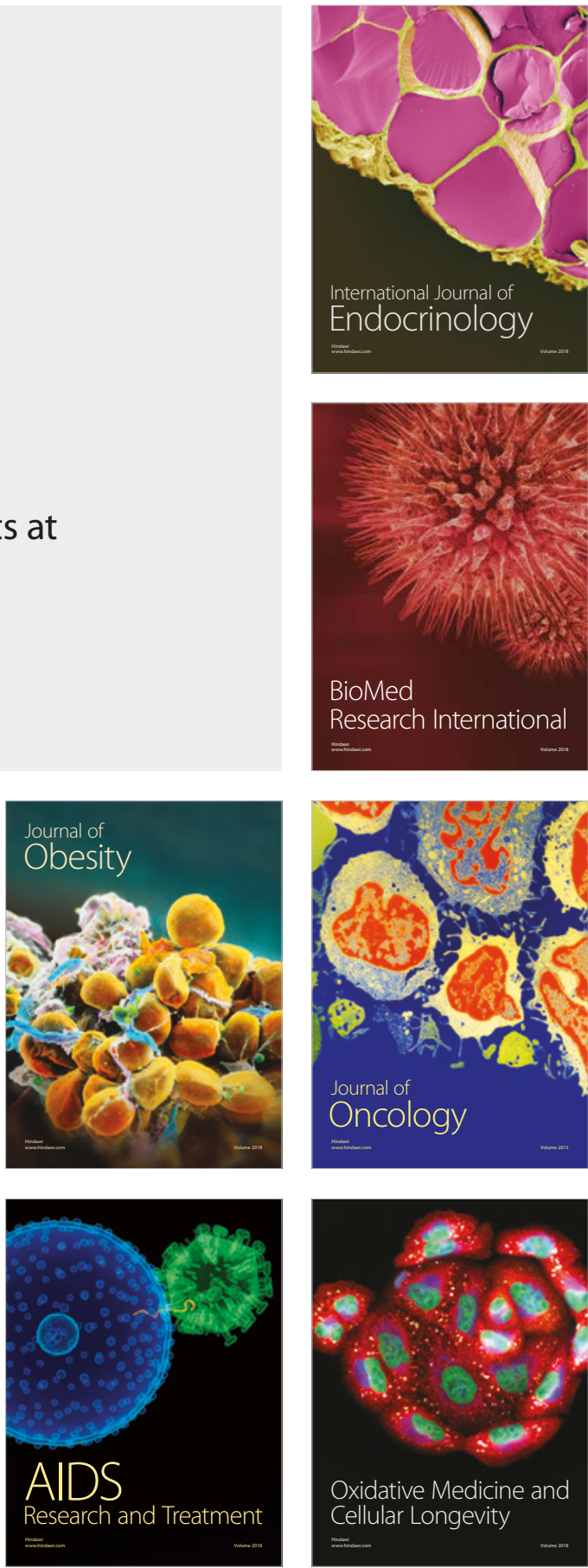